\title{
مقاربة نظرية لوصف أداء العاملين في ظل بعض خصائص المناخ التنظيمي
}

A theoretical approach to describing the employees' performance in light of some characteristics of the organizational climate

\author{
تاريخ الاستلام : 2019/09/24 ؛ تاريخ القبول : 2020/01/26
}

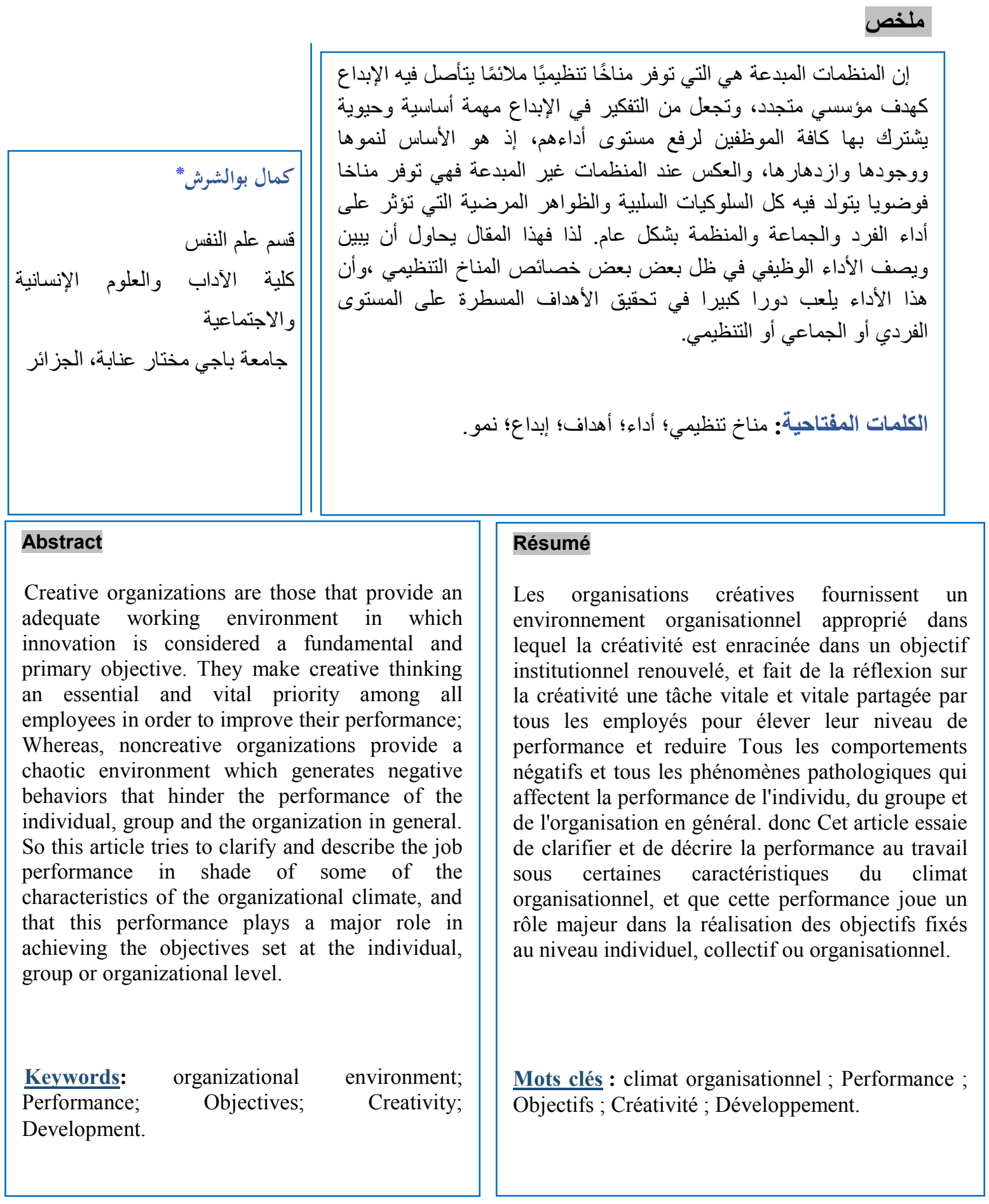

*Corresponding author, e-mail: laouinette1985@yahoo.com

$$
\text { (C) جامعة الاخوة منتوري قسنطينة 1، الجز ائر2020. }
$$


بتطلب نجاح المنظمات في تحقيق أهدافها المخطط لها توافر عدد من المتغيرات

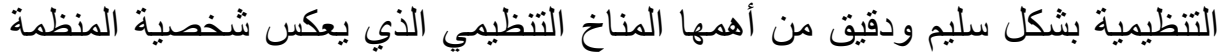

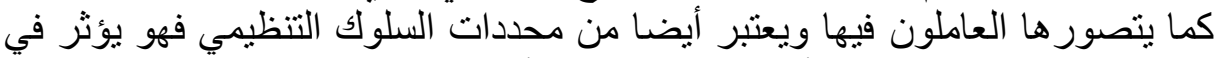

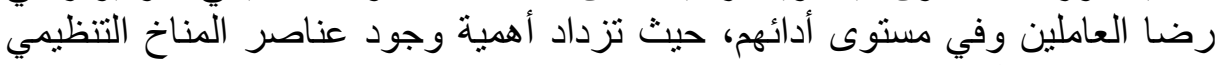

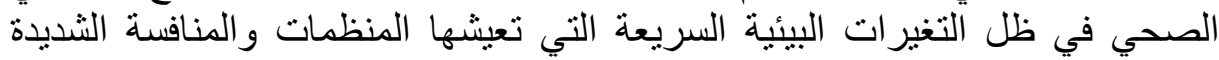

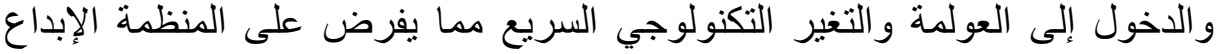

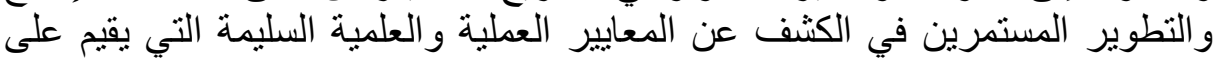

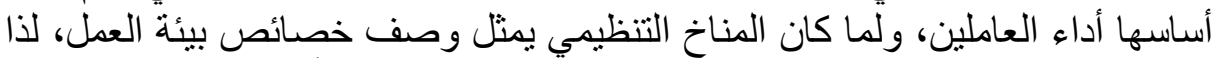

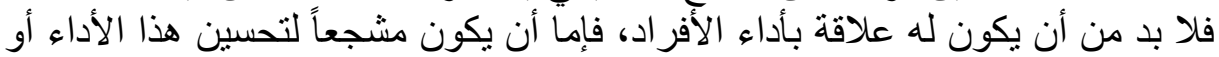

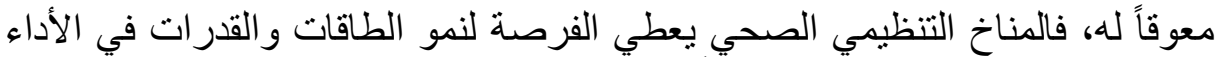

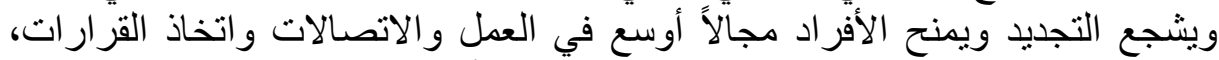

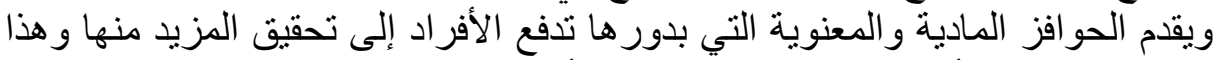

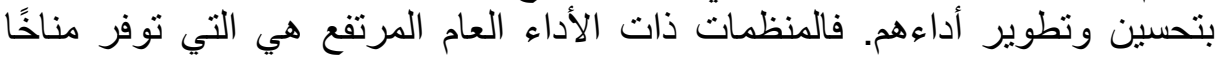

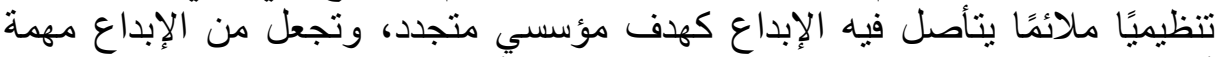

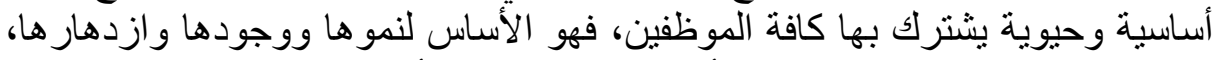

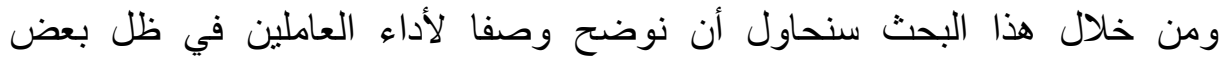
خصائص المناخ التنظيمي، و هذا بعد أن نعطي مقاربة نظرية حول ما كتب عن الني المناخ

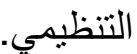

1 1-مفهوم المناخ التظيمي: عرف مفهوم المناخ التنظيمي جدلا كبيرا بين الباحثين

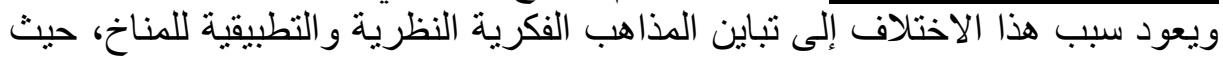

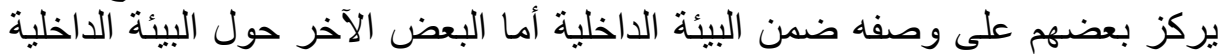

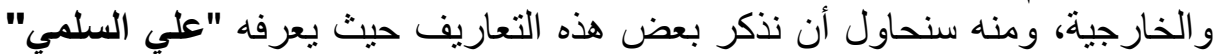

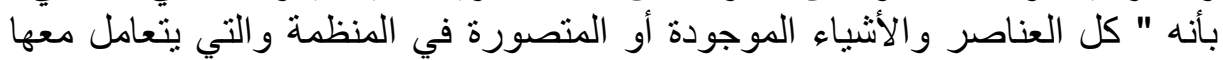

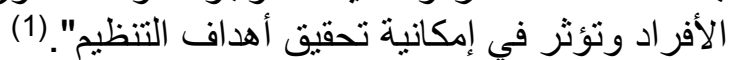
كما عرفه "محمد علي شهيب" على أنه " تعبير عن الخصائص المختلفة لبيئة

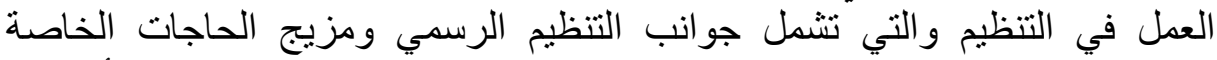

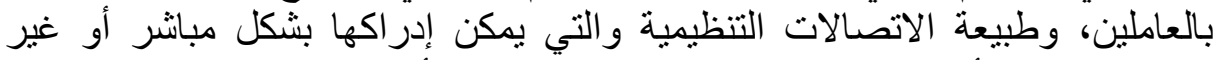

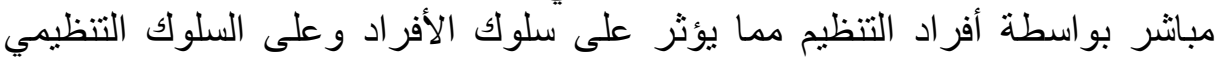
ككل، و لاشك أن ذلك كله يتداخل ويؤثر في إمكانية التنظيم في تحفيق التئ الفعالية في

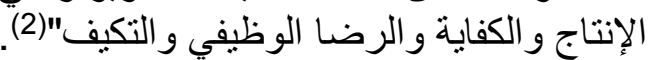
ويعرفه "شنيدر Schneider "على أنه " ملخص التها إدرالك الأفراد لشخصية

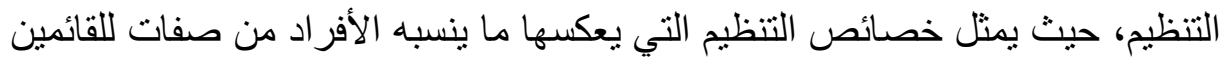

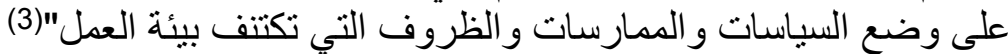
ويرى" ذنيبات" أن المناخ التنظيمي "هو تعبير مجازي النيات يستخدم في الإدارة للإلالة

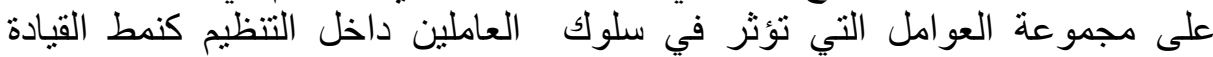

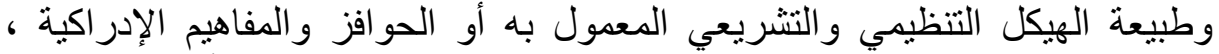

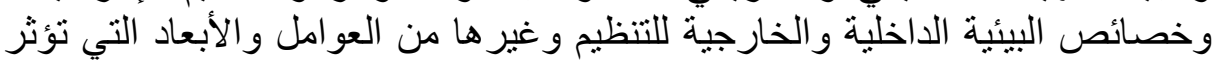

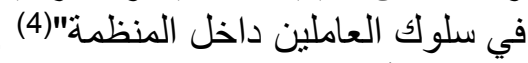
ويرى "فورهاند وجلمر Forhand and Gelmer "أن المناخ التنظيمي "هو

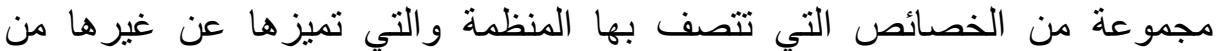

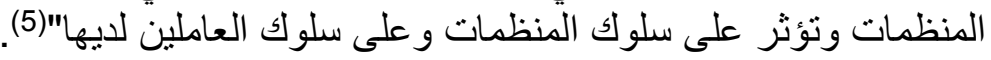




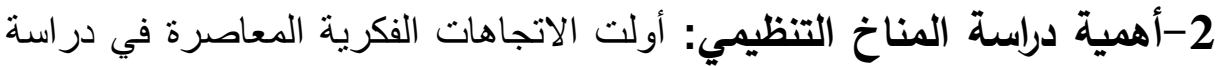

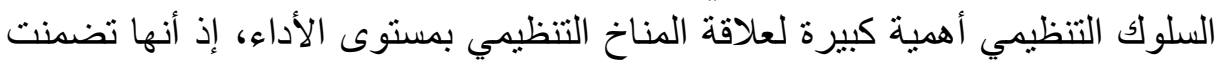

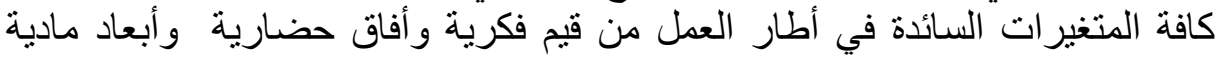

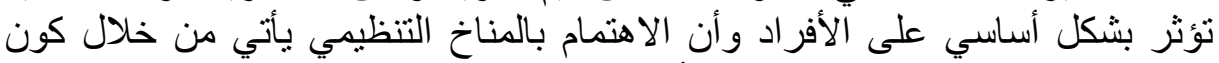

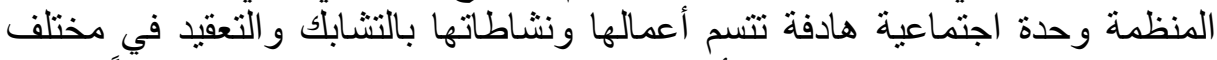

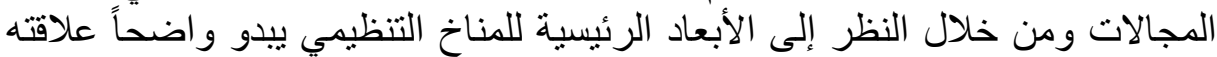

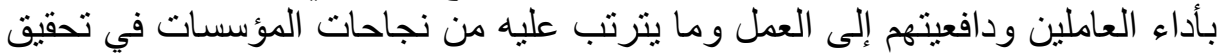

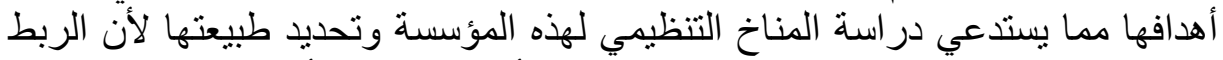

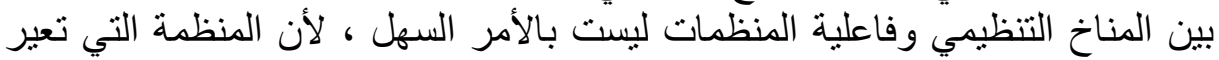

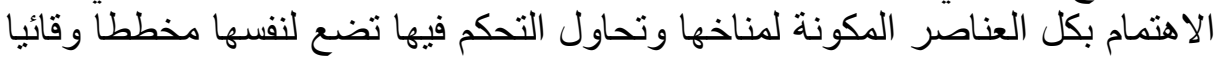

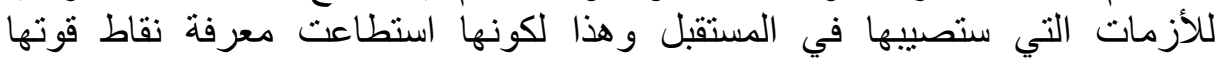

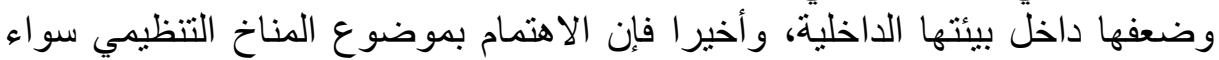

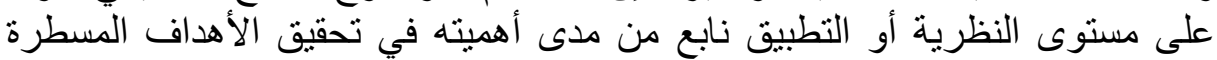

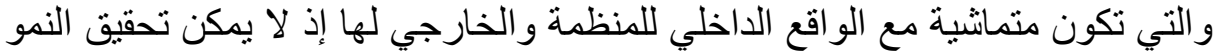

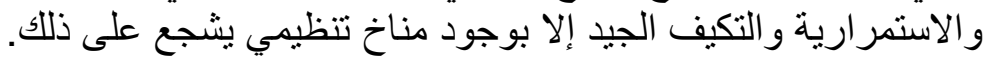

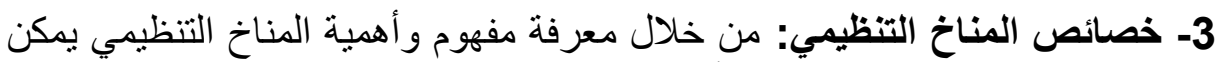

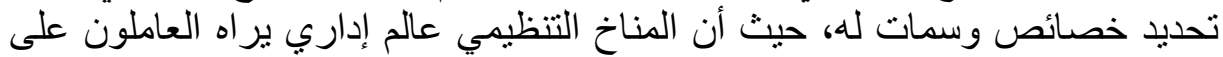

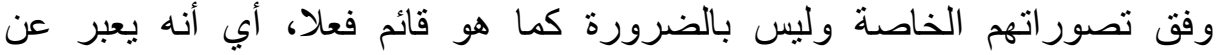

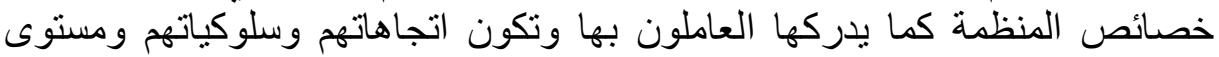

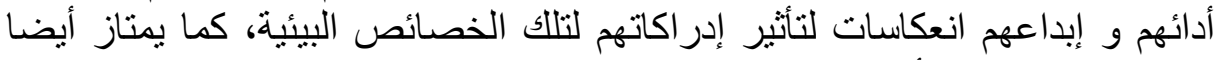

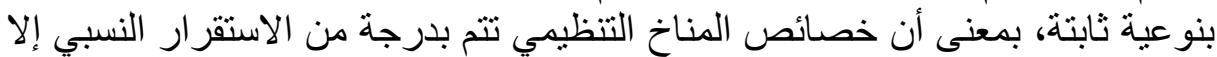

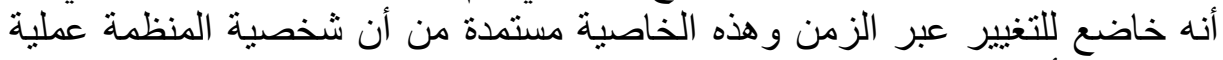

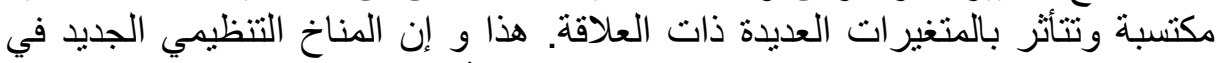

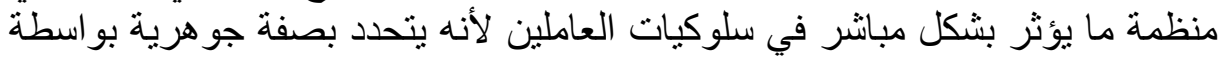

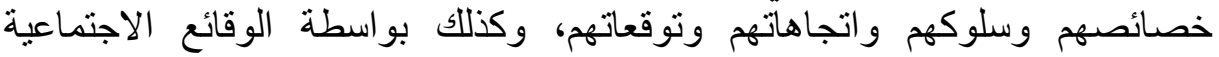

و الثقافية.

\section{4- 1-4 بعض عناصر المناخ التنظيمي:}

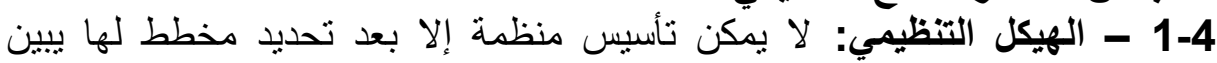

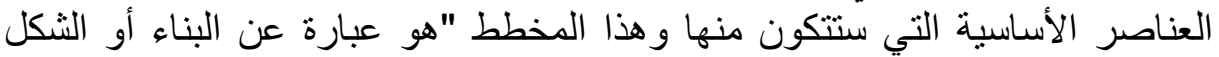

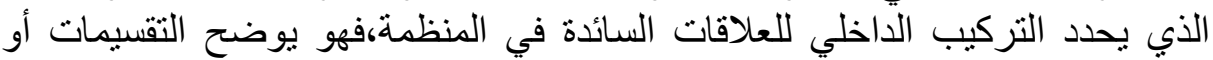

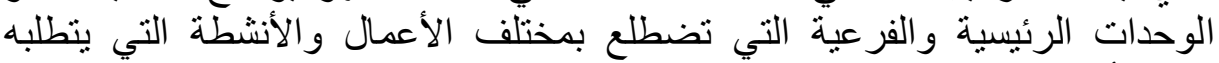

تحقيق أهداف المنظمة" (6) الهبية.

ويرى "حريم" أن للهيكل التنظيمي معنى محدد ولكنه معقد فيقول أن الهيكل

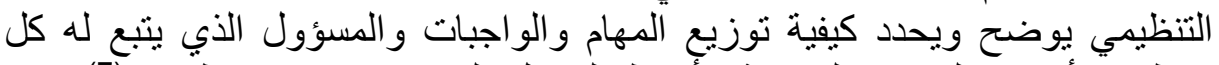

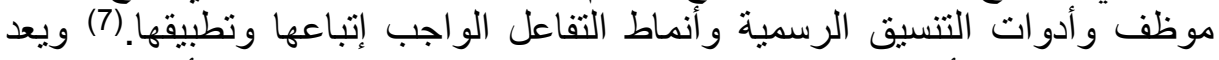

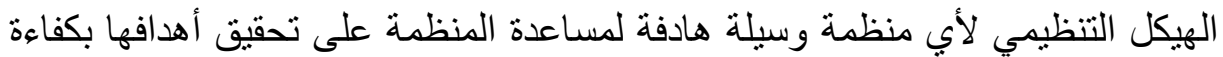

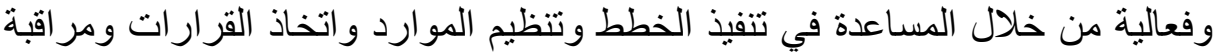

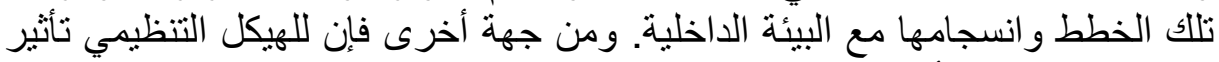

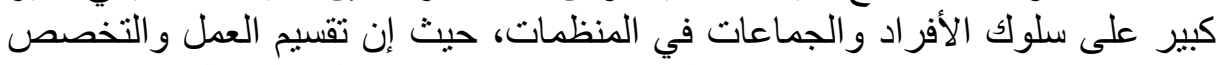

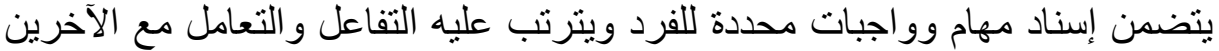

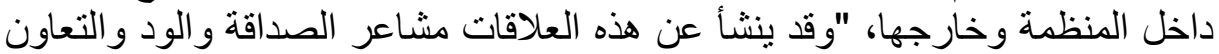

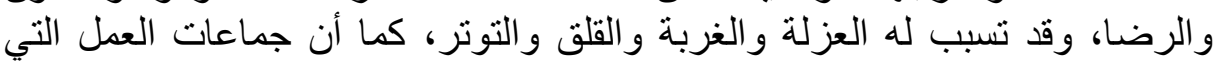


يعمل الفرد معها قد تكون كبيرة أو قليلة العدد وقد تضم أفرادا يقومون بأعمال متجانسة أو متباينة، و هذا يؤثز على درجة تماسك الجماعة ومدى التفاعلات والاتصات التصالات فيما

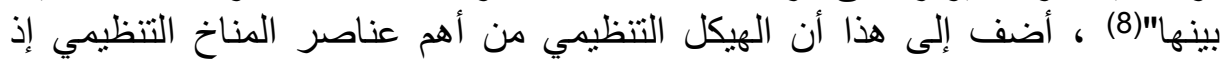

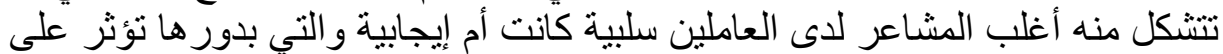

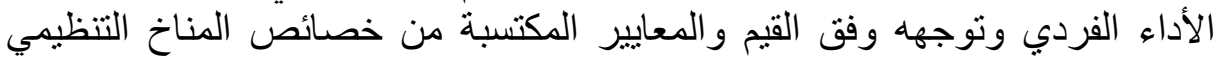

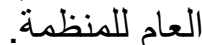

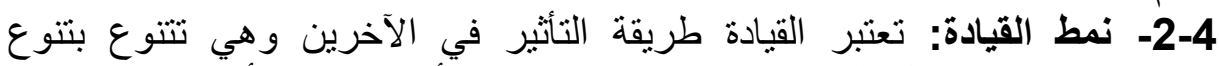

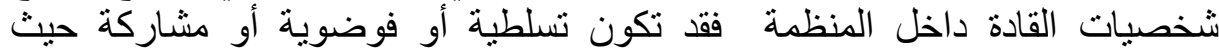

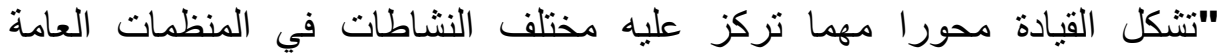

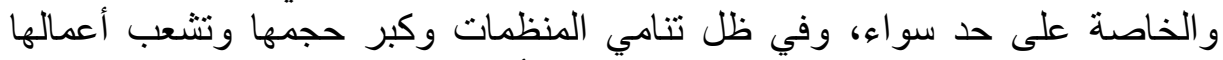

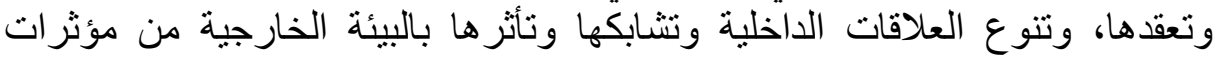

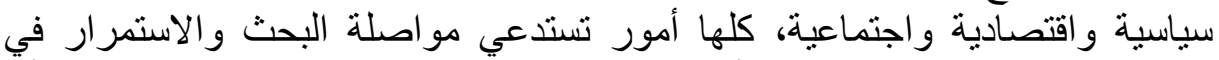

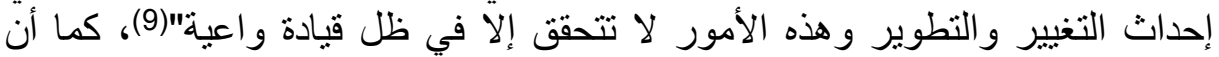

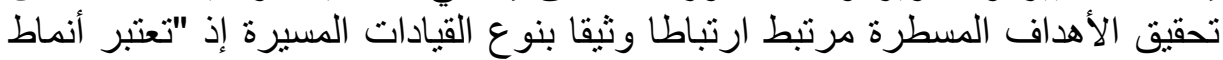

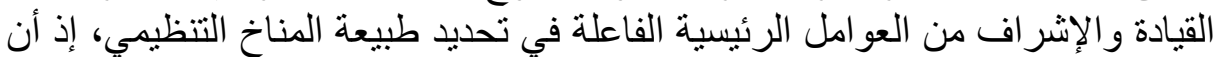

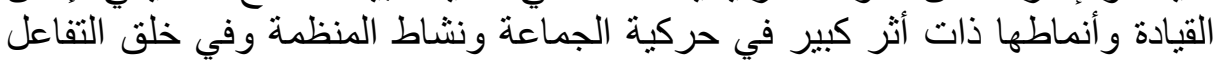

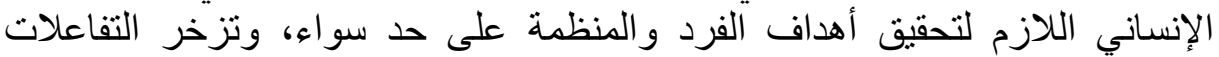

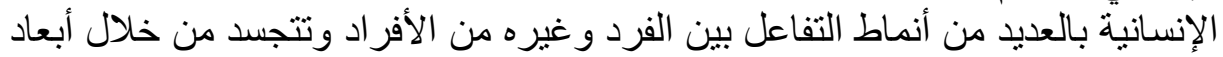

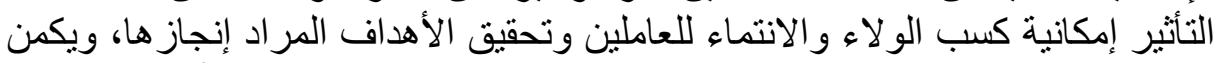

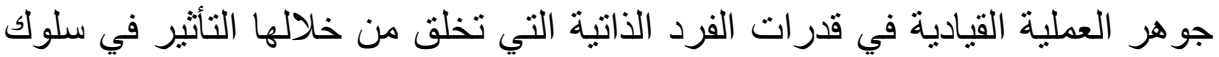

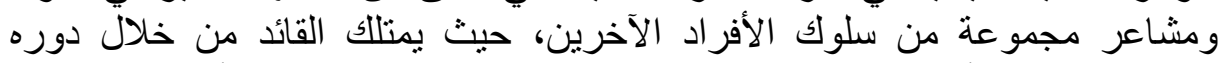

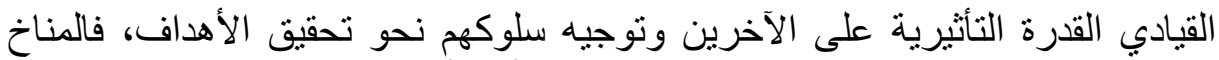

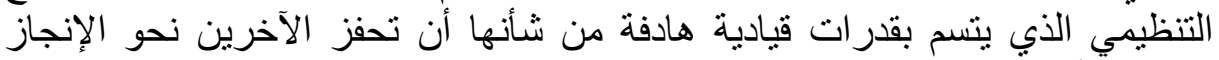

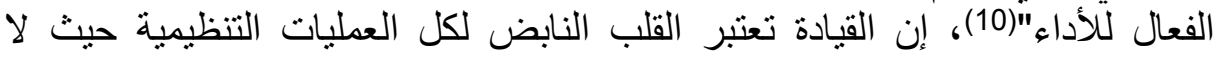

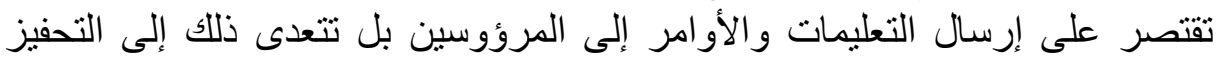

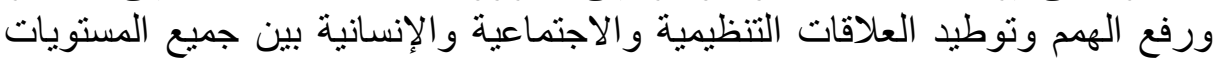

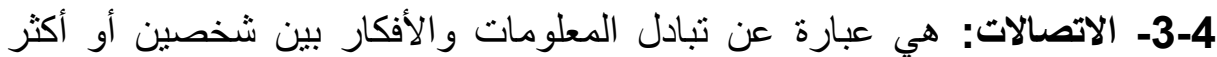

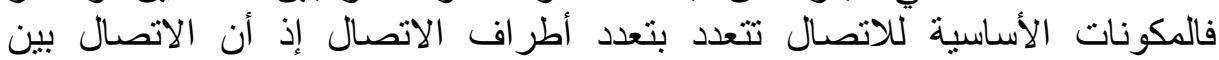

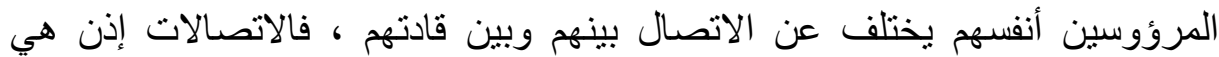

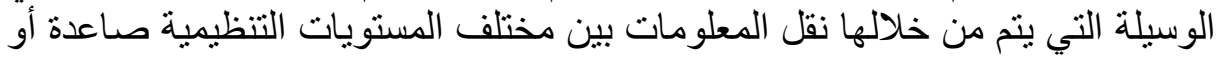

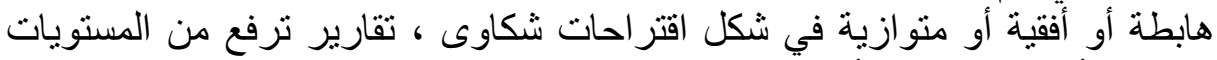

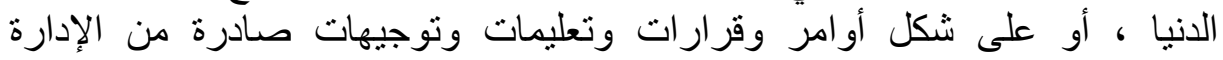

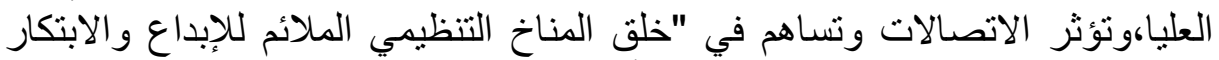

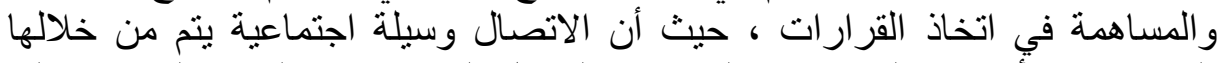

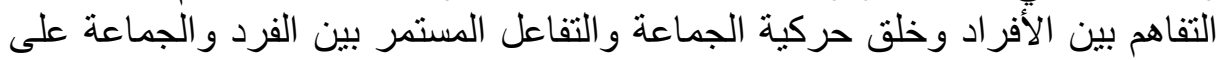

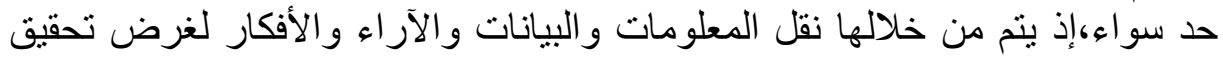

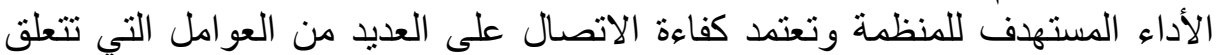

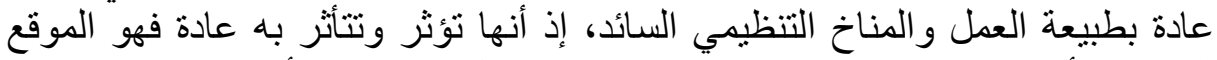

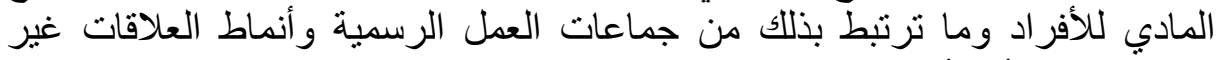

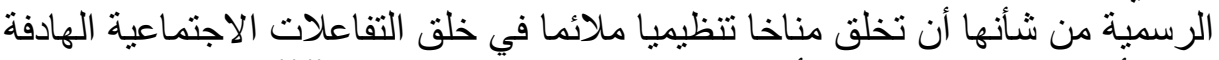

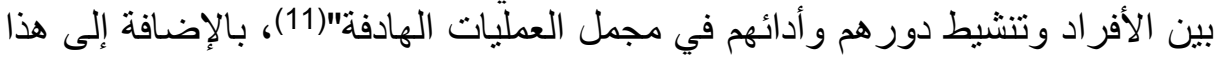

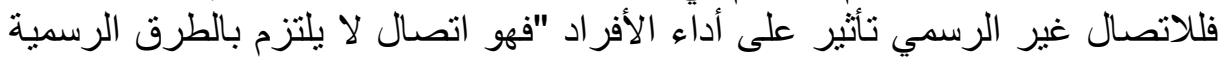


المتعارف عليها في الاتصال الرسمي ولا يخضع لأي إجراءات أو قواعد أو قوانين

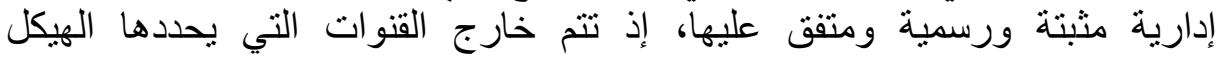

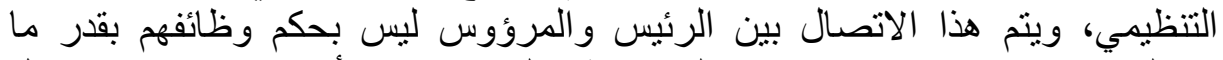

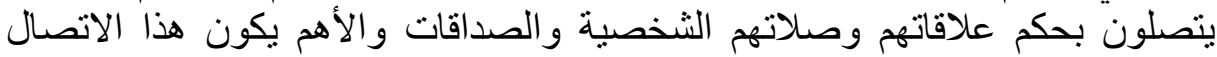

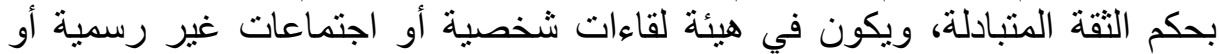

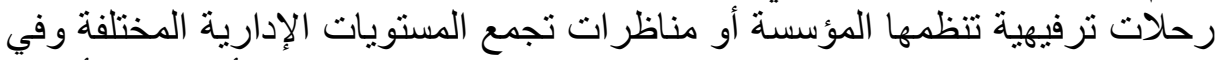

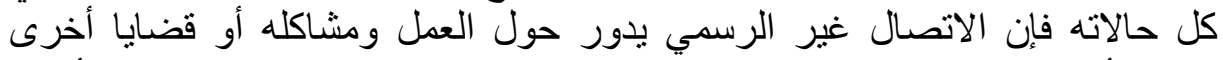

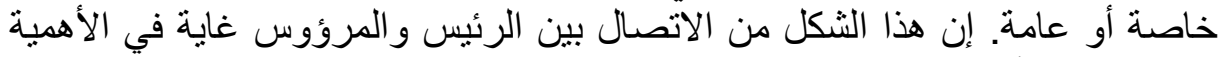

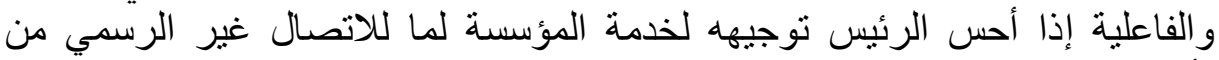

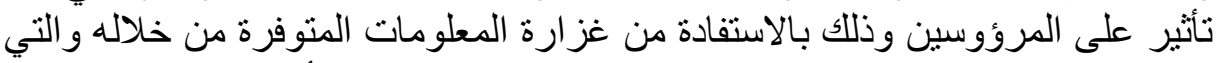

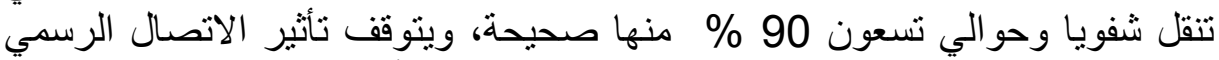

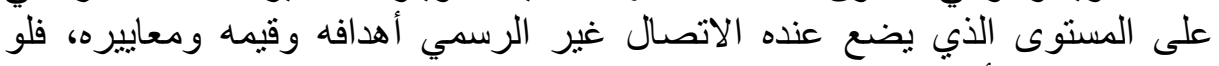

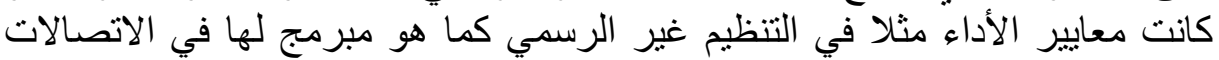

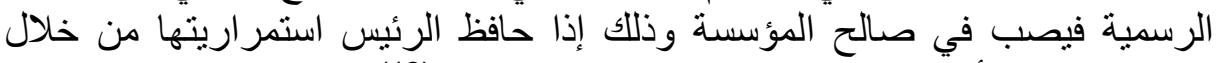

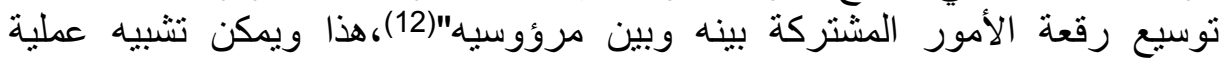
الاتصال بالمؤسسة بالجهاز العصبي الناقل للسيالات العصبية فئرونية فبدونها يصاب الجسد

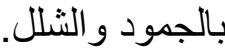

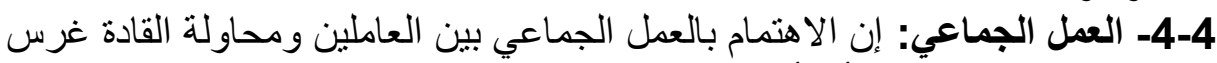

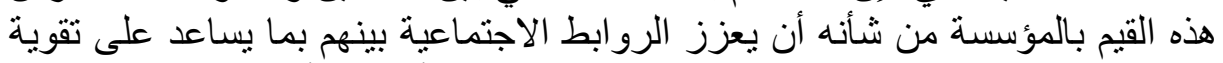

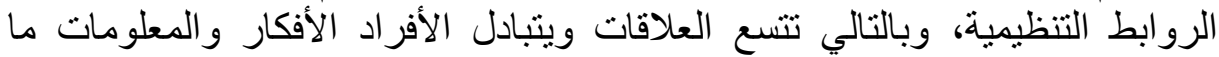

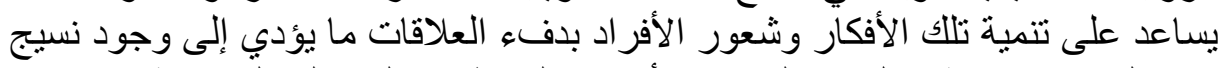

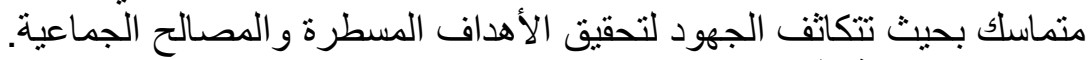

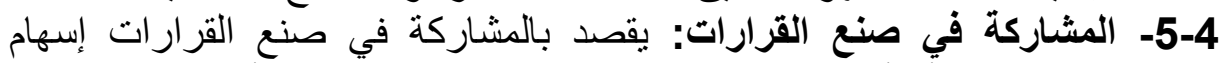

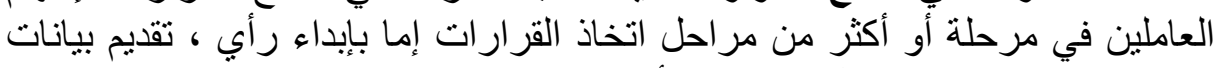

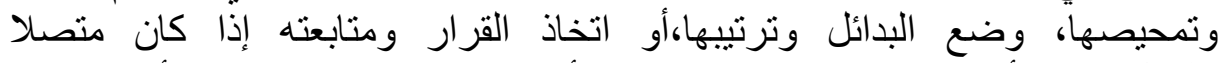

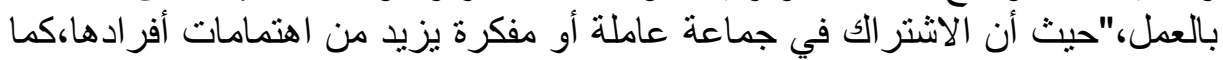

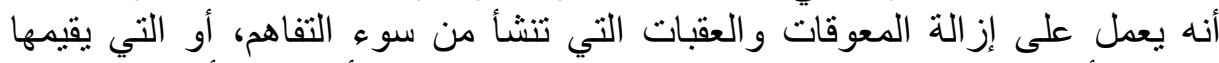

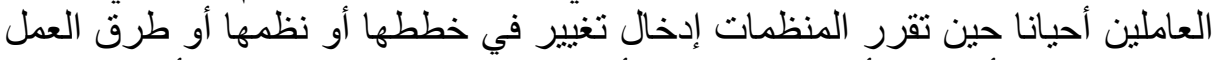

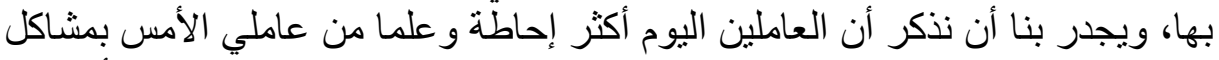

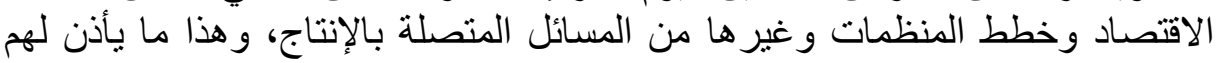

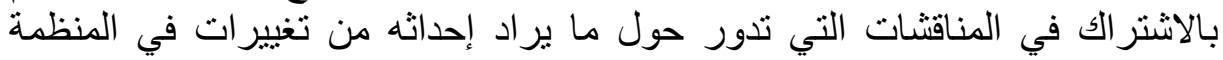

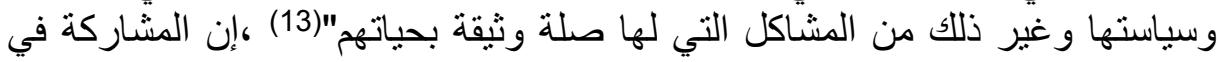

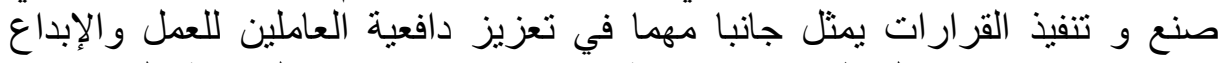

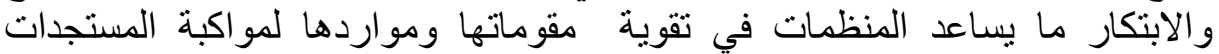

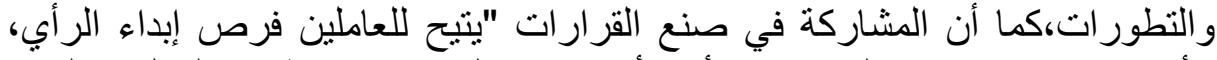

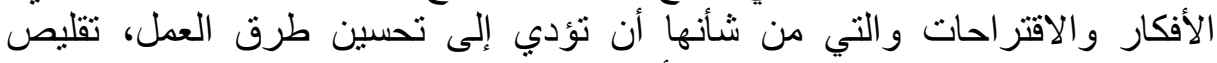

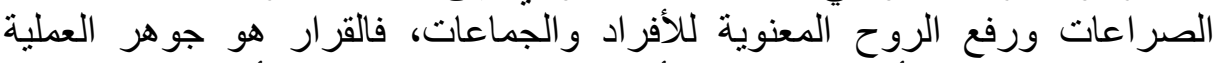

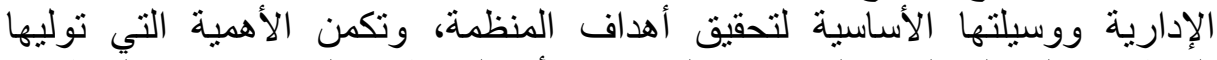

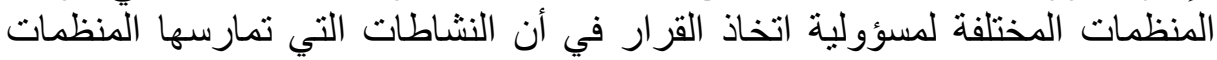

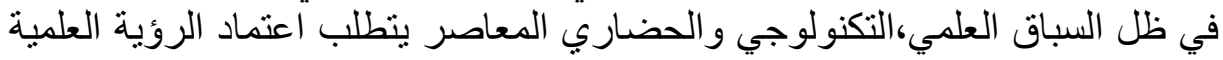

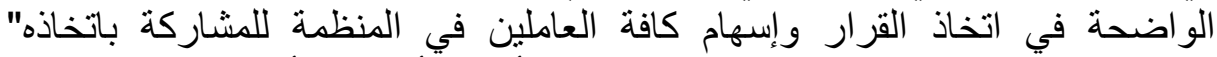

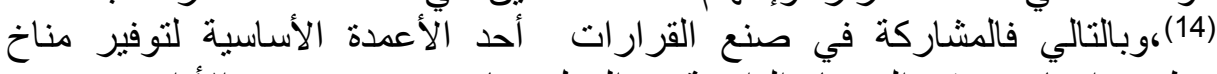

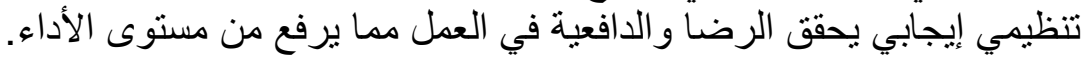


6-4- الحوافز: لا يمكن لأي تنظيم بشري اجتمع على تحقيق أهداف إلا وكان هنالك

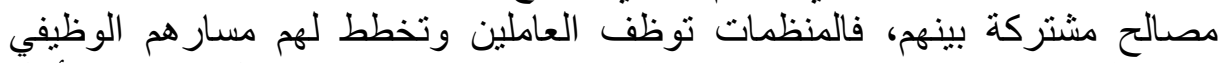

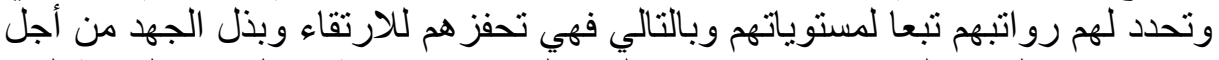

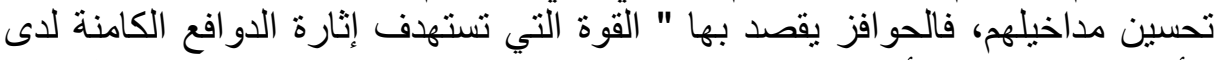

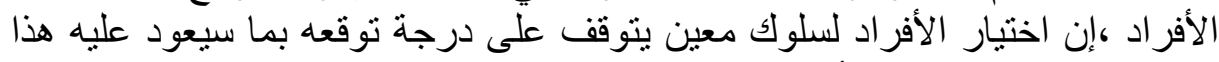

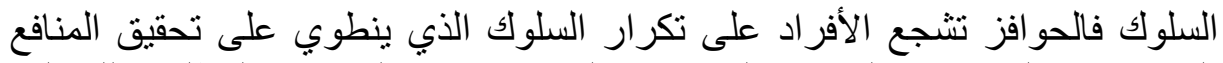

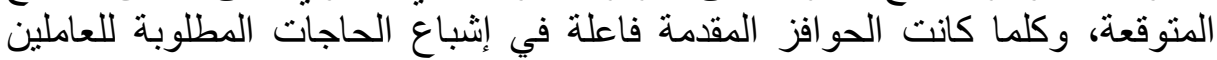

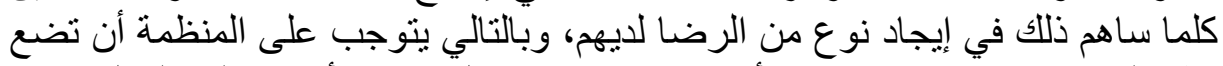

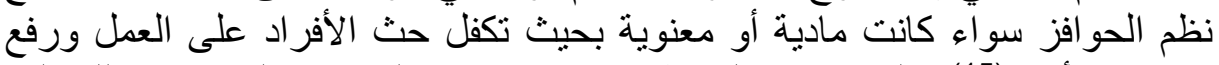

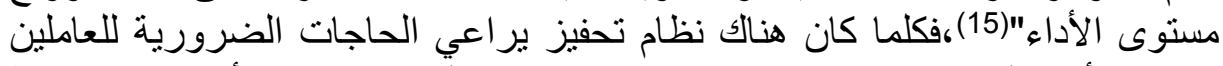

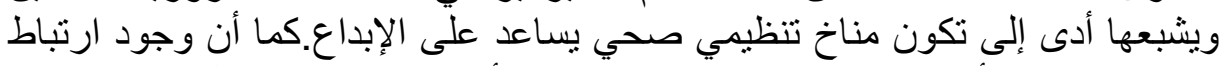

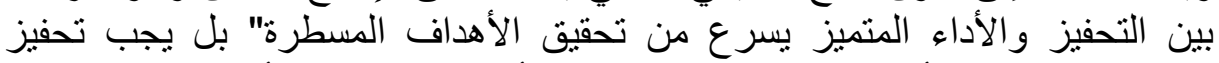

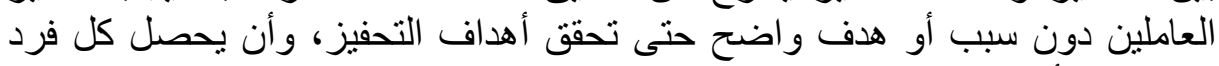

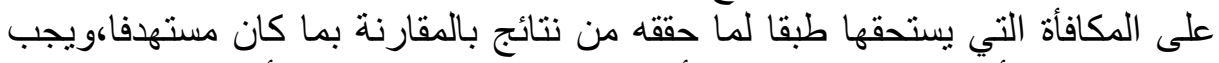

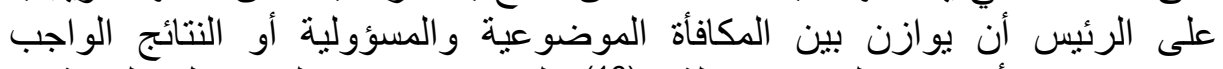

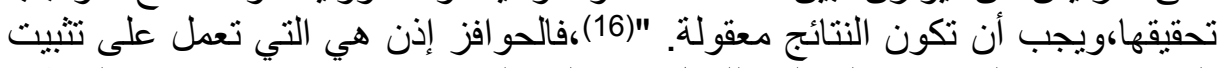

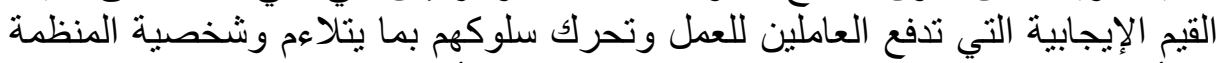

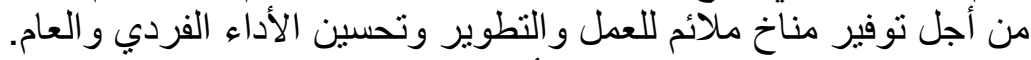

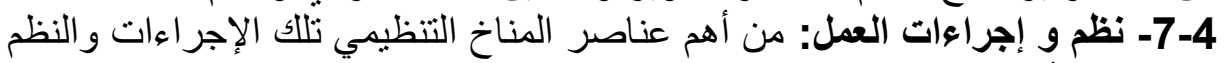

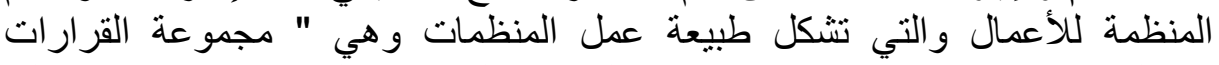

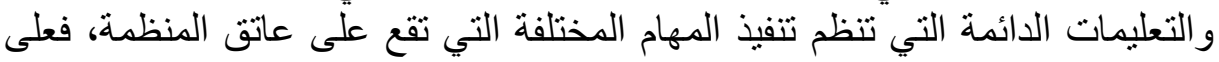

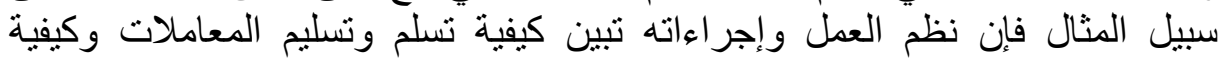

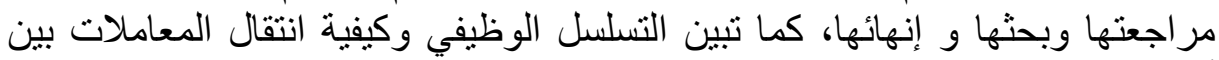

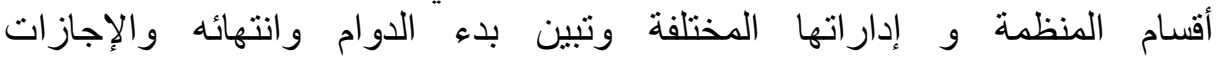

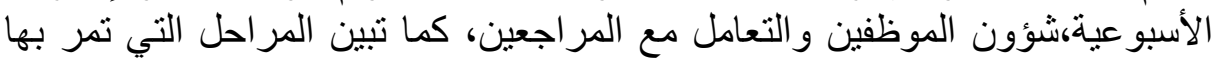

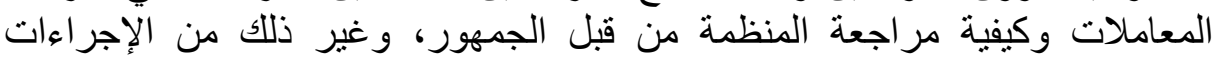

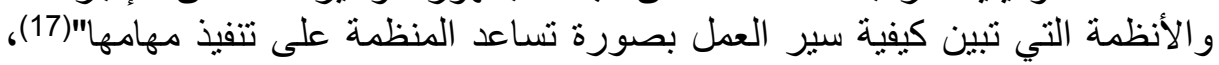

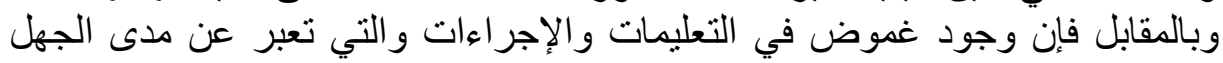

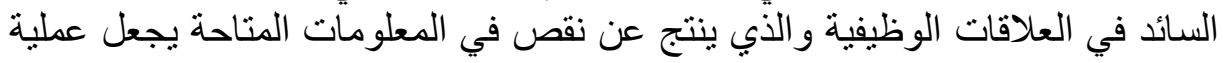

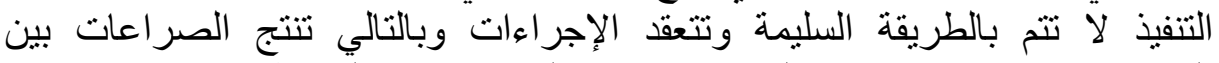

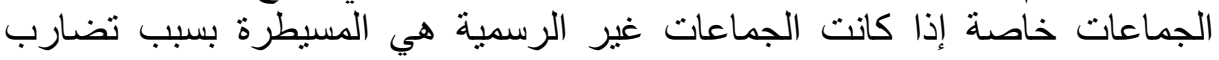

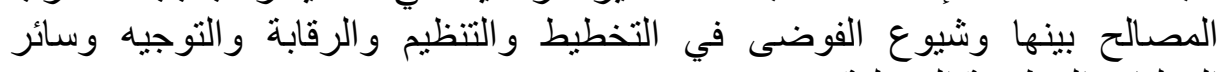
العمليات التنظيمية المختلفة.

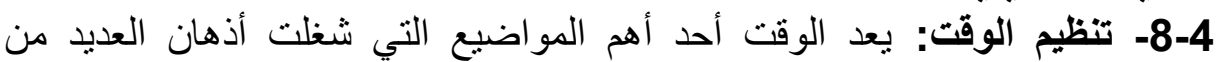

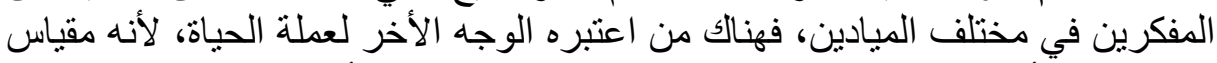

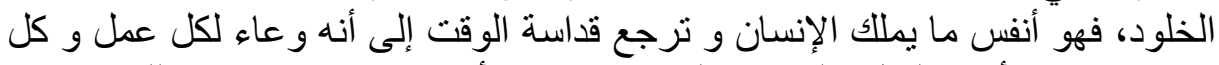

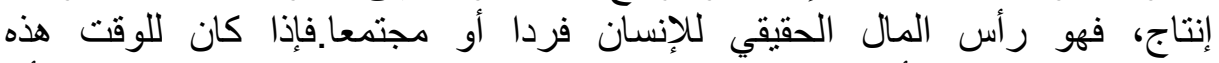

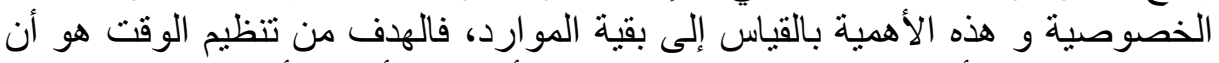

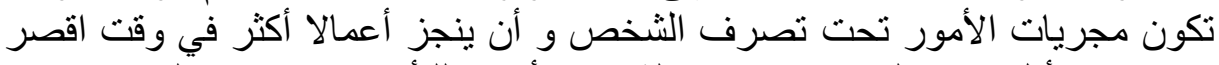

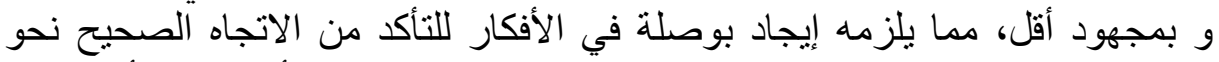

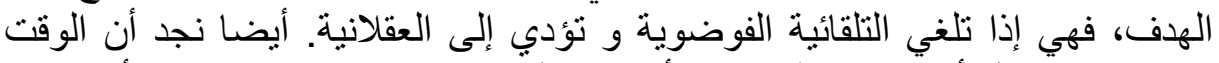

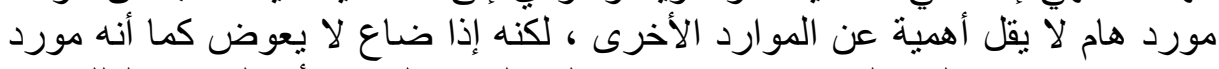

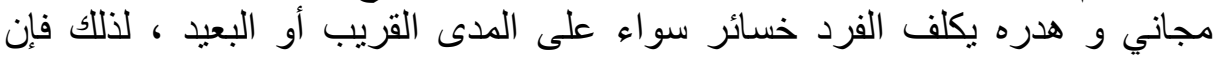


فعالية إدارة هذا المورد تعتبر ضرورة ملحة سواء على مستوى الفرد أو المؤسسة ،

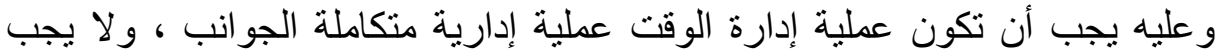

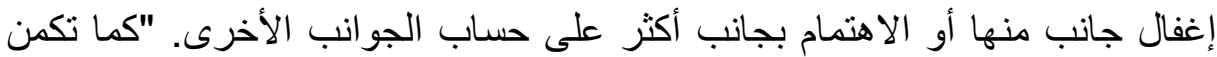

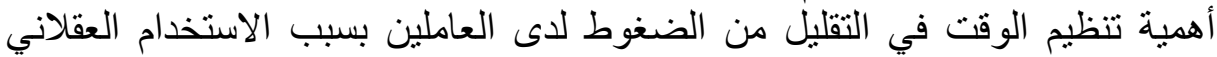

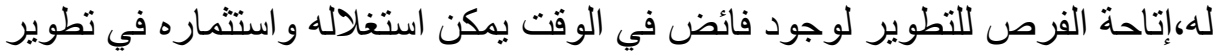

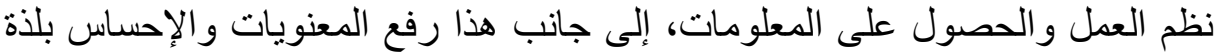

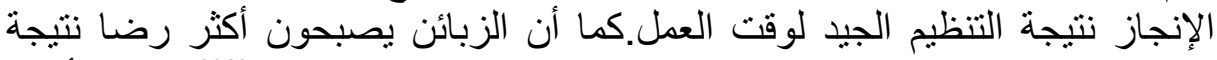

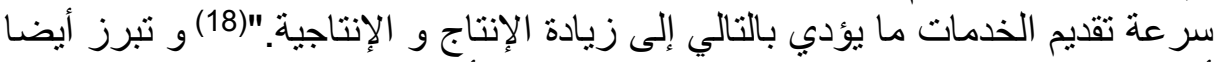

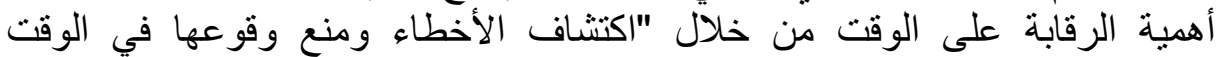

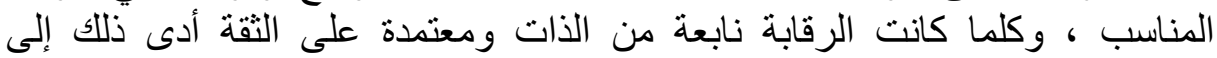

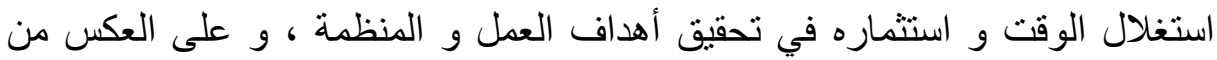

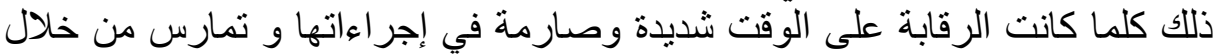

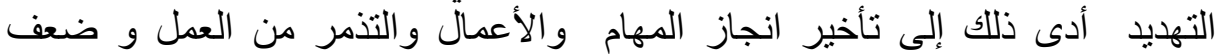

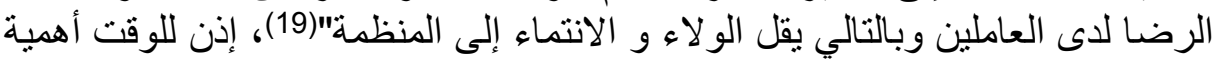

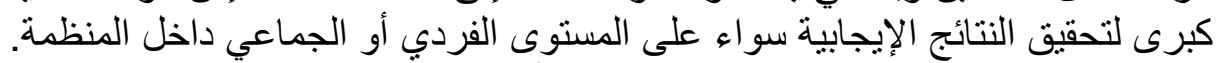

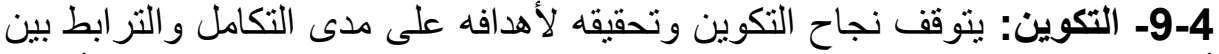

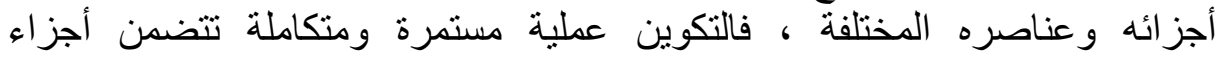

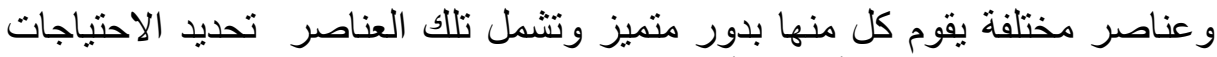

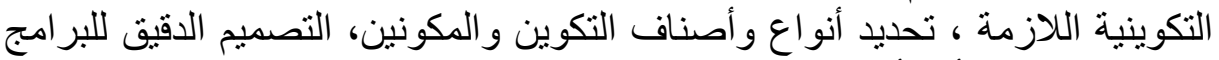

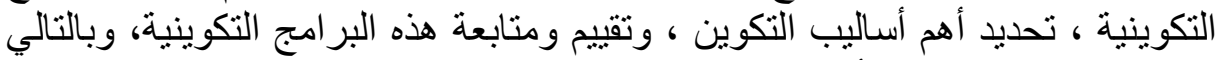

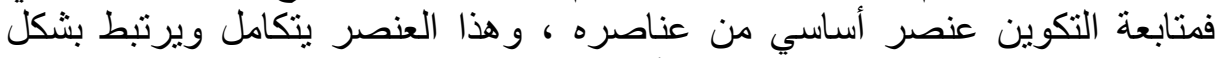

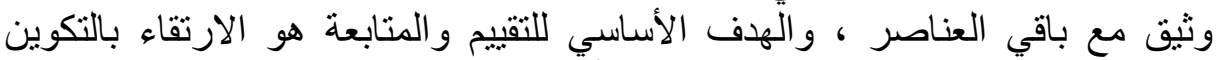

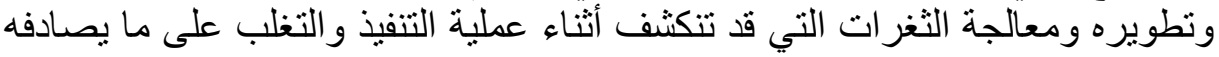

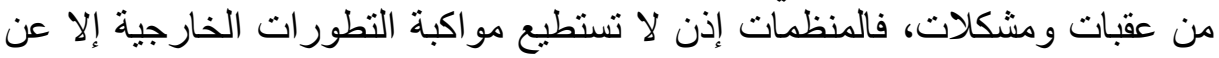

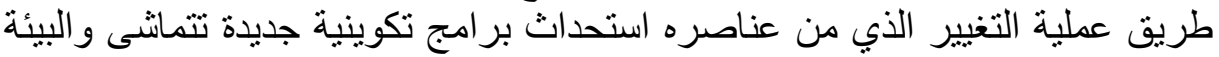

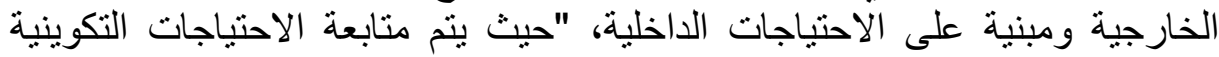

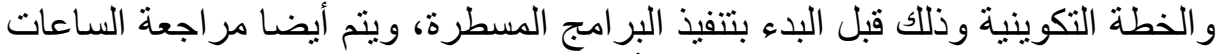

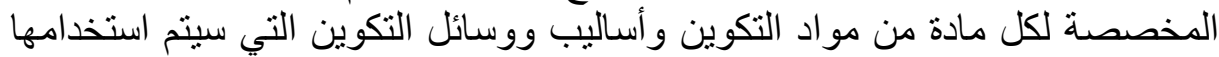

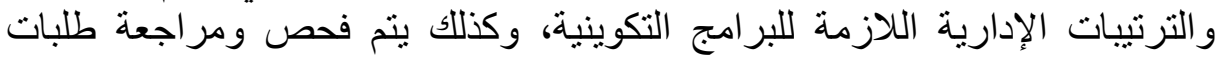

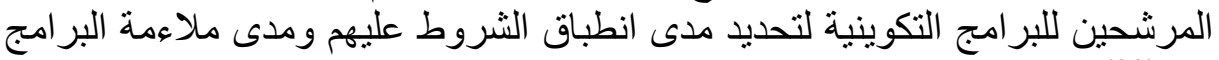

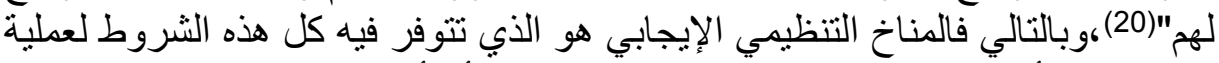

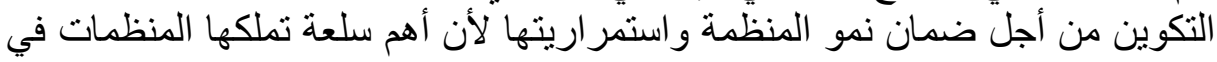

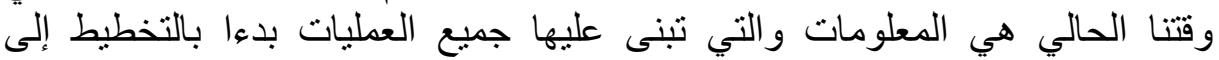

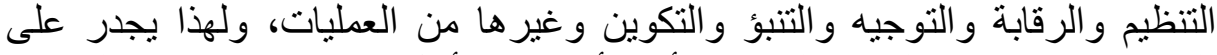

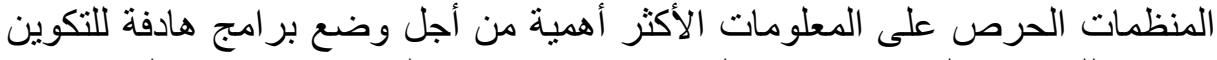

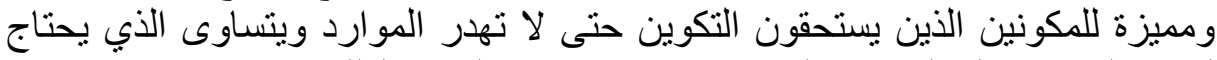

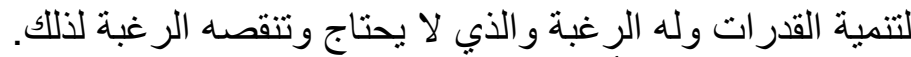

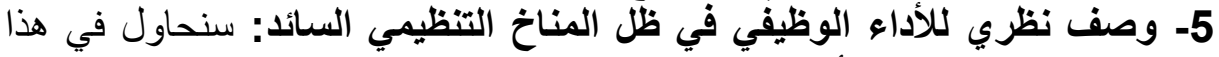

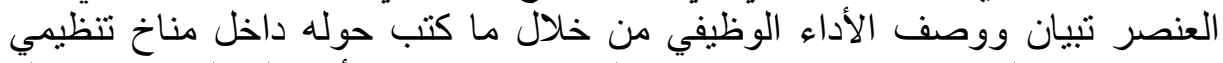

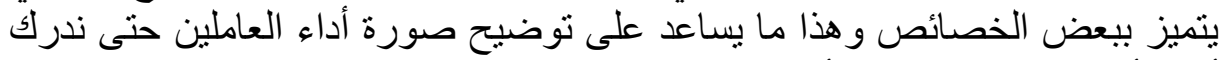

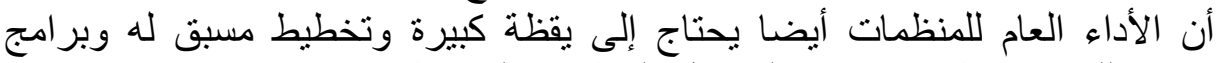

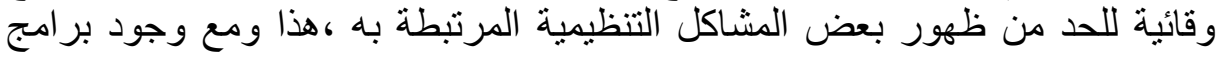

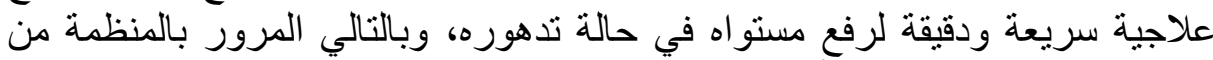

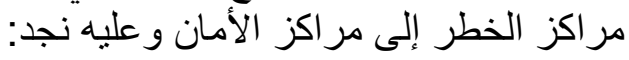




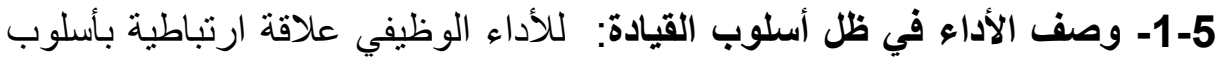

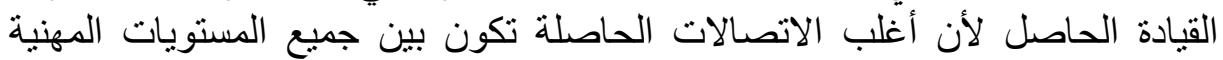

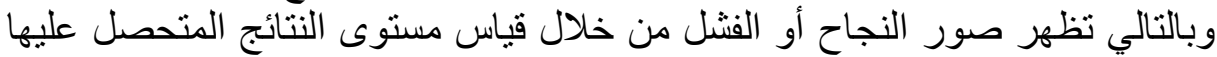

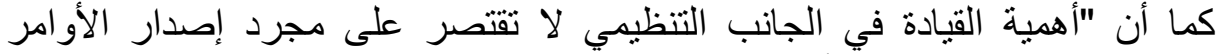

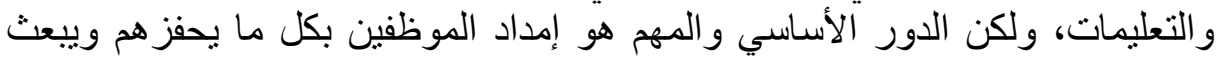

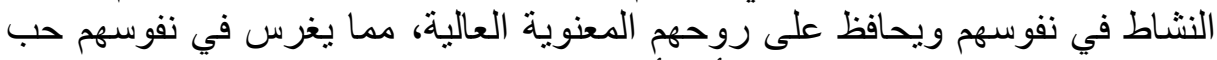

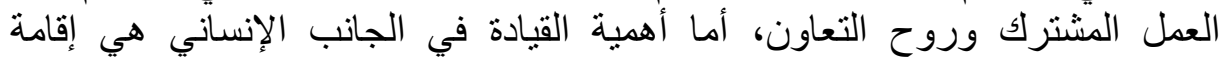

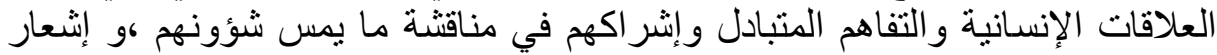

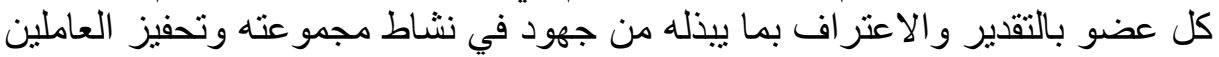

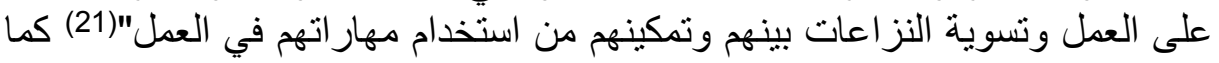

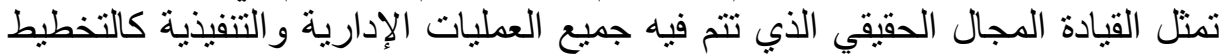

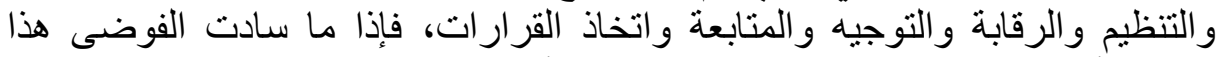

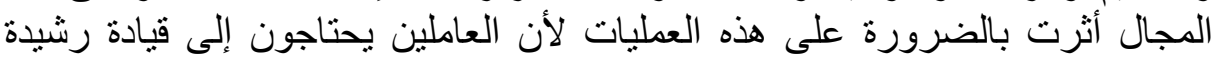

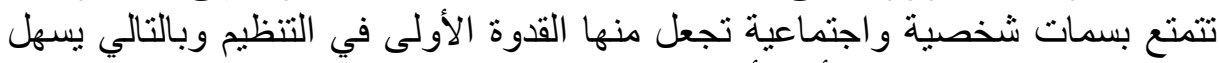

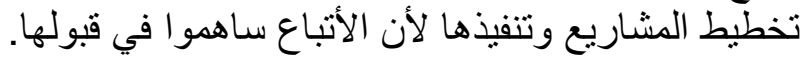

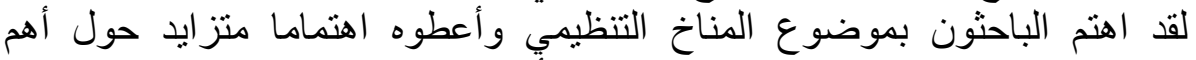

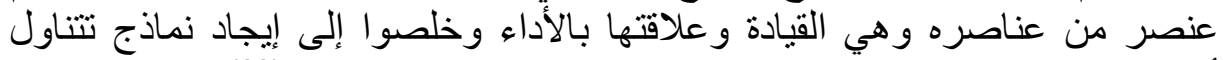

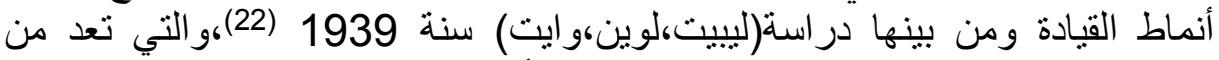

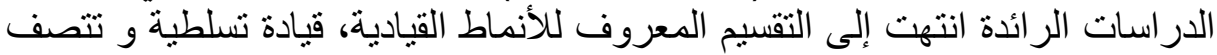

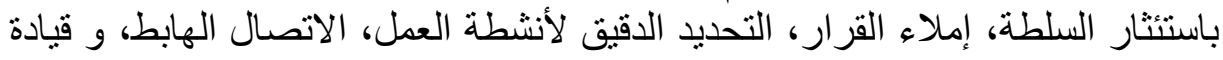

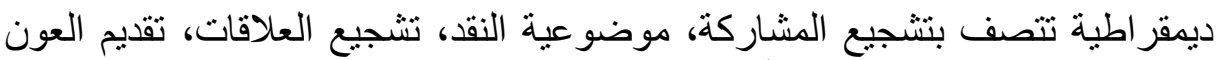

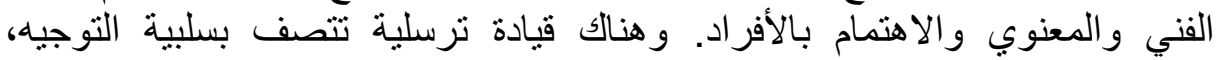

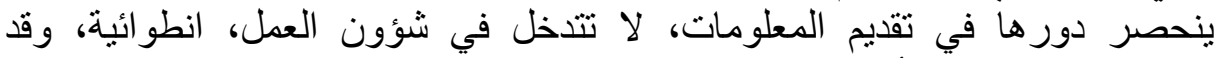

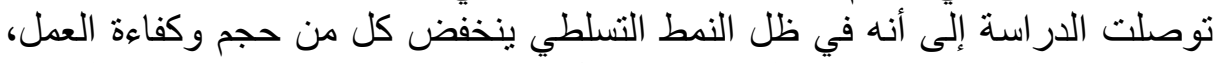

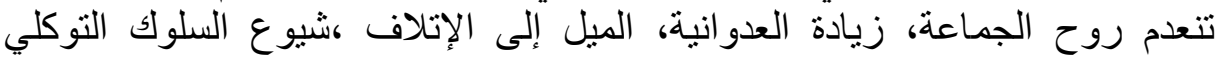

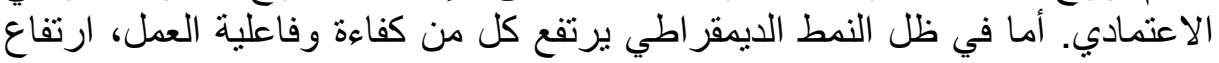

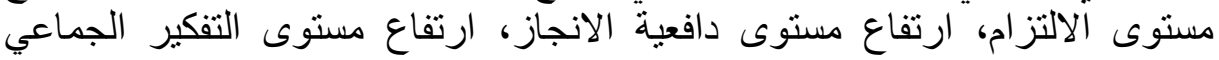

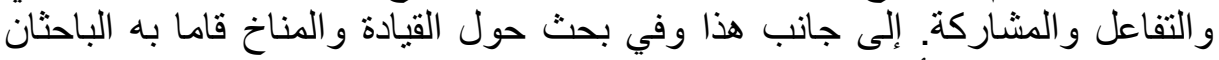

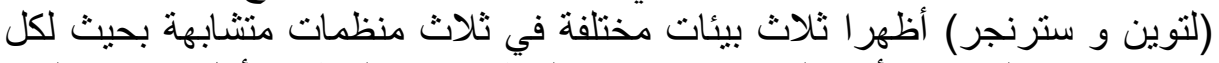

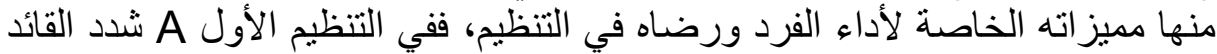

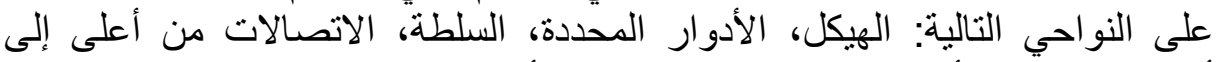

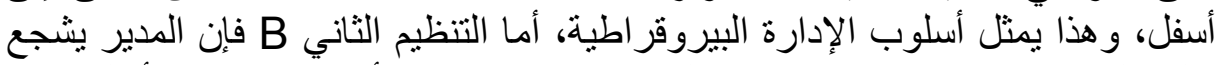

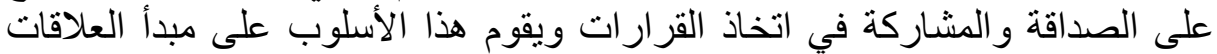

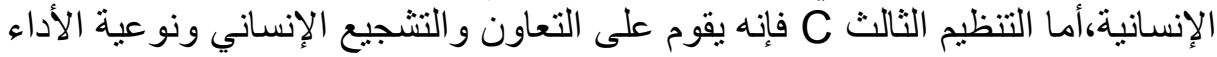

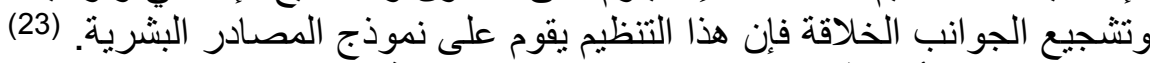

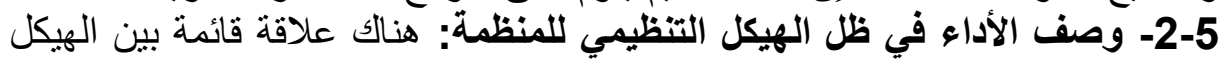

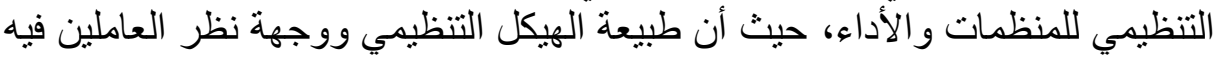

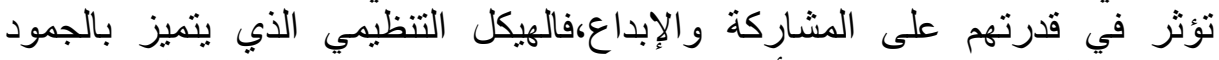

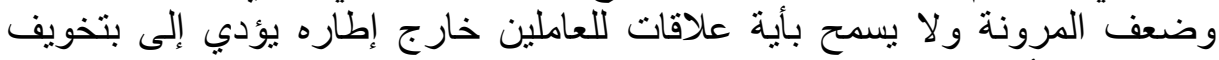

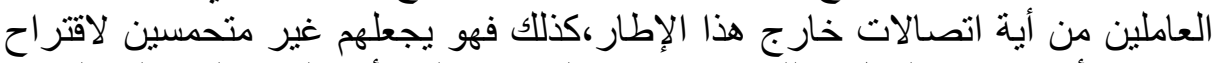

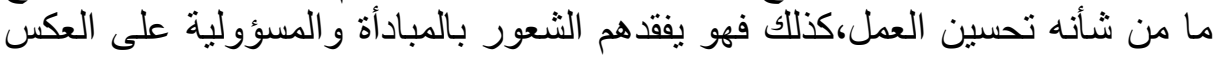

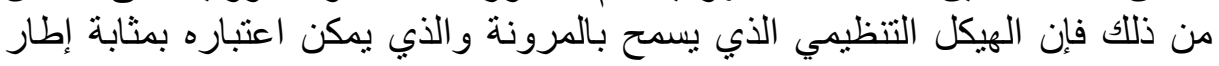




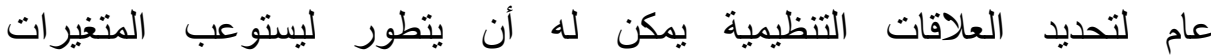

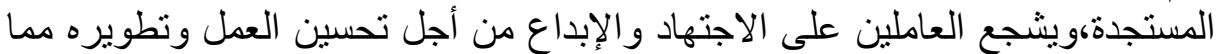

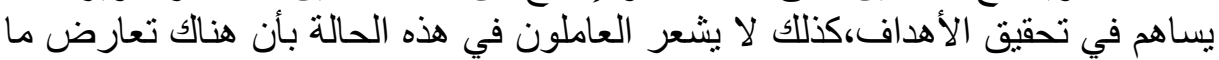

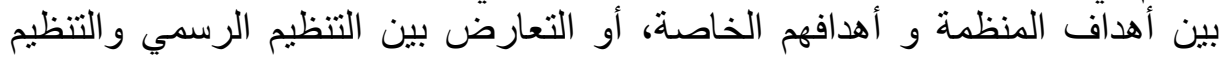

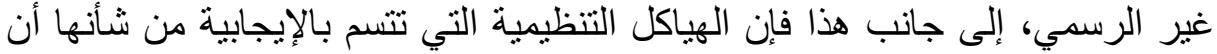

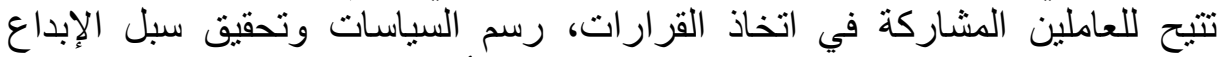

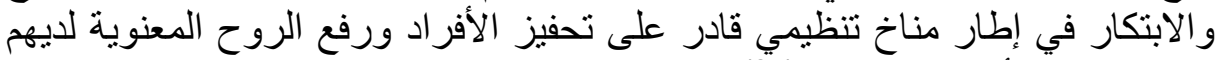

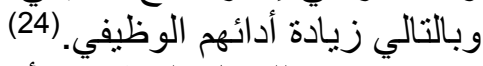

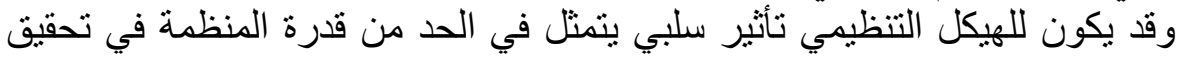

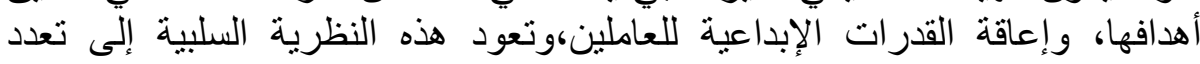

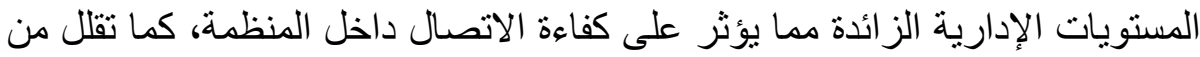

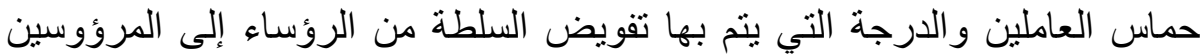

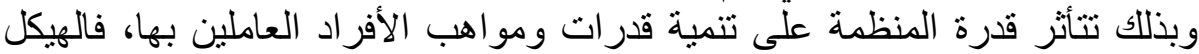

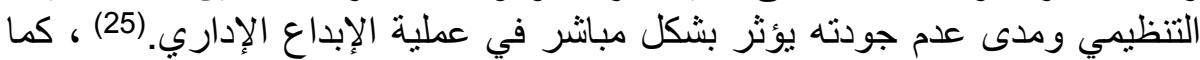

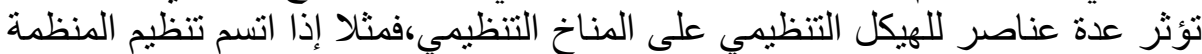

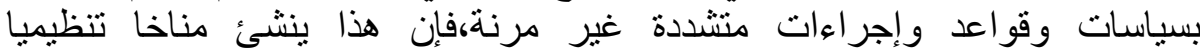
بيروقراطيا وهو مناخ سيدركه العاملون على أنه رسمي جامد وفئنة وغير محفز للأداء

الوظيفي المثنمر وزيادة الإنتاجية.

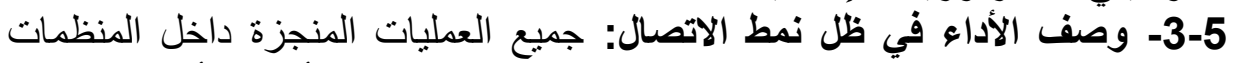

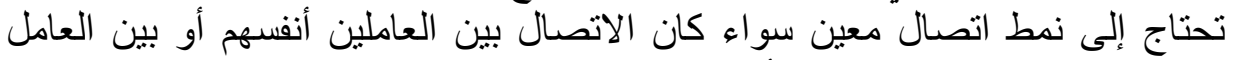

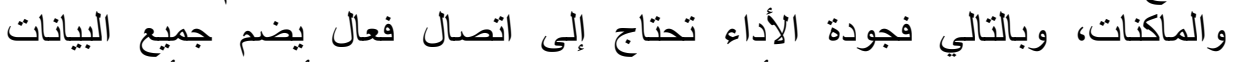

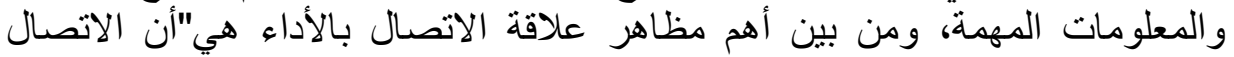

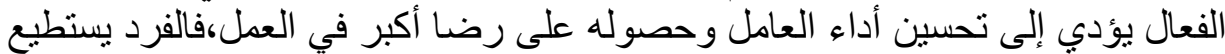

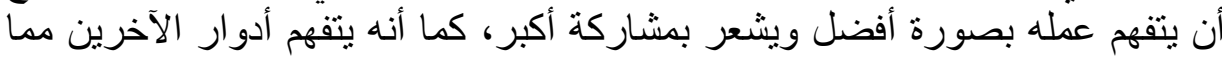

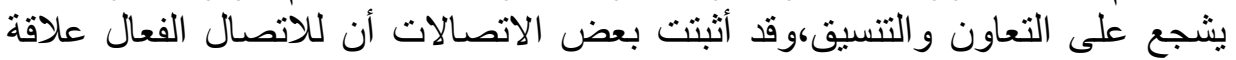

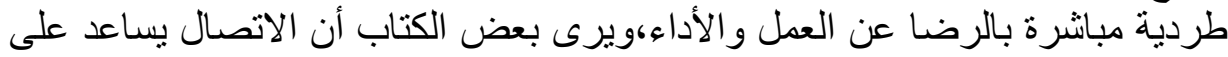

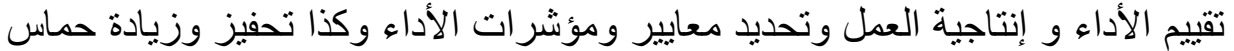

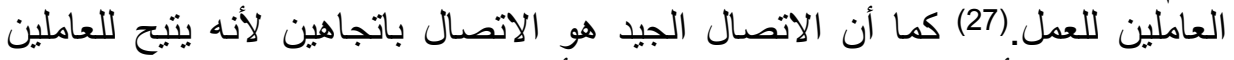

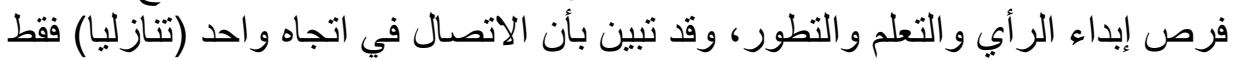

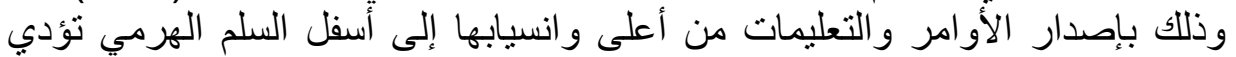

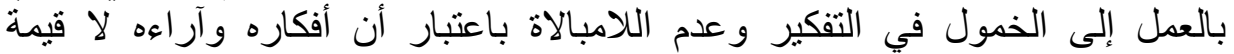

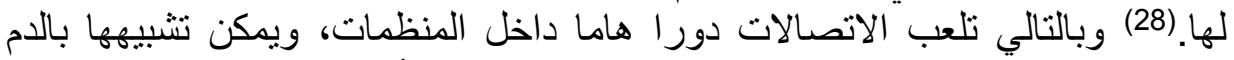

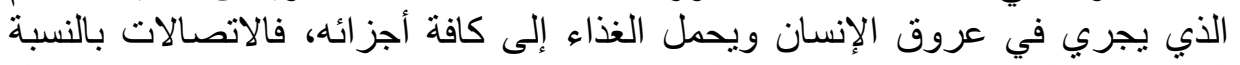

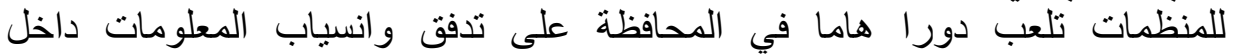

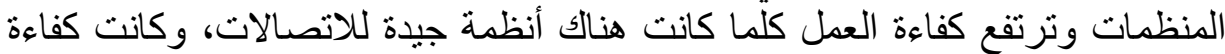

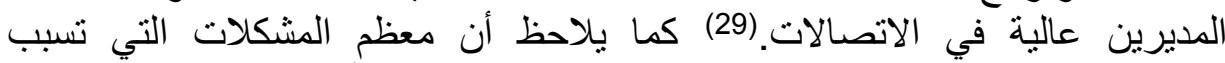

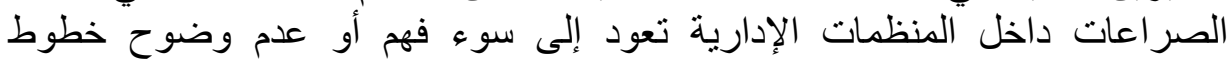

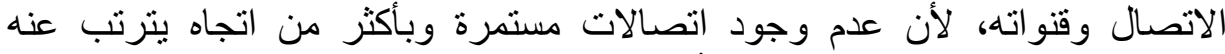

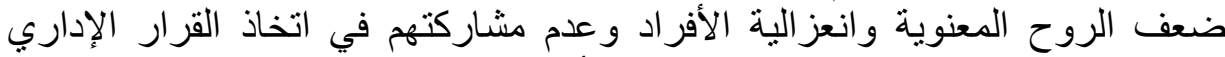

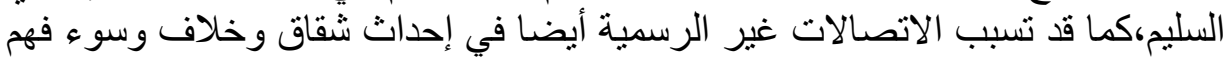

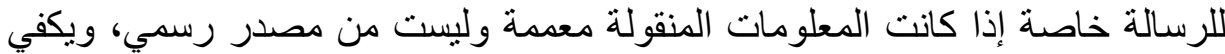
أن تحتوي بعض الحقائق لكي يتم تصديقها،فمن هذا المنطلق يحدث الخات الخلل أو الخطأ في فهم الأوامر والتعليمات وبالتالي الخطأ في إدارة الأعمال والأفراد واد والخطأ في أداء أداء

(30) (30) 
4-5- وصف الأداء في ظل المشاركة في اتخاذ القرارات: تعتبر عملية اتخاذ القرار

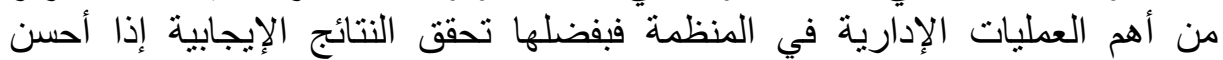

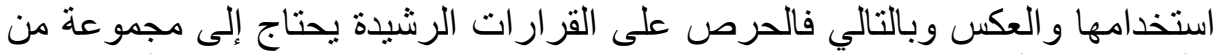

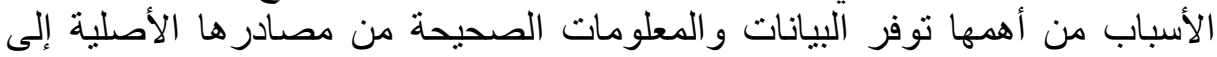

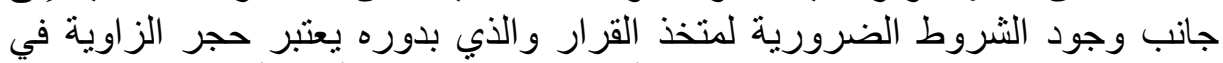

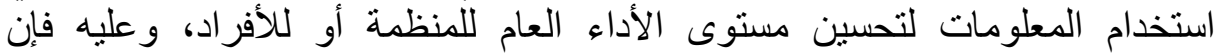

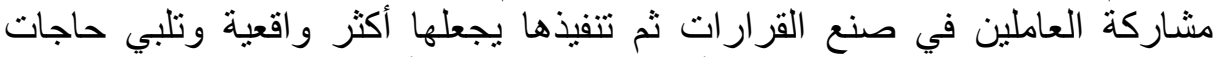

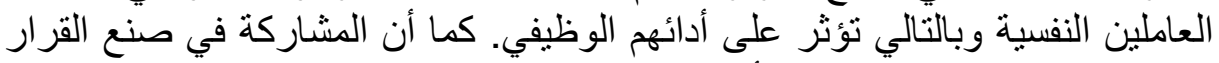

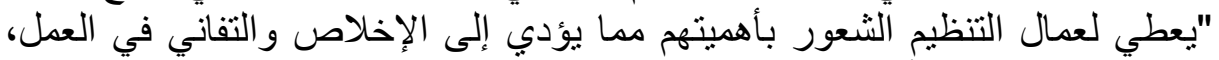

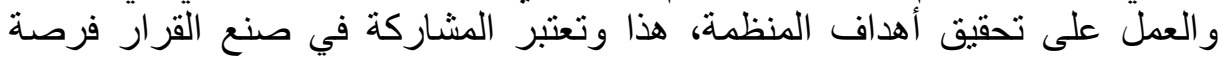

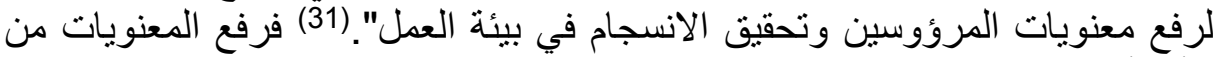

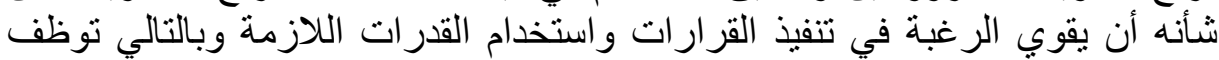

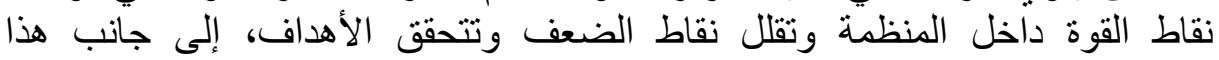

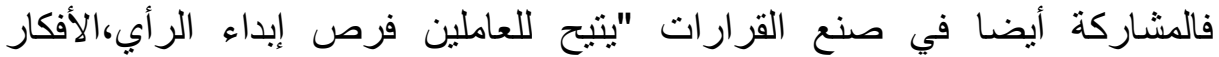

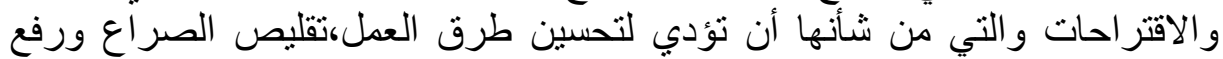

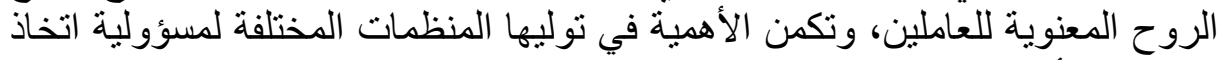

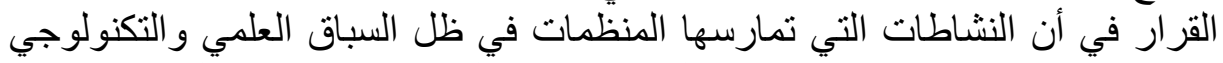

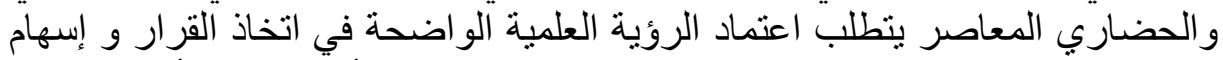

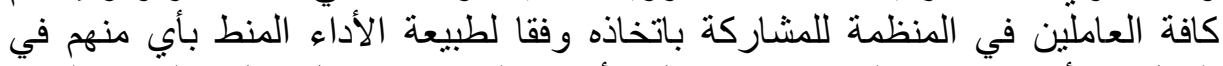

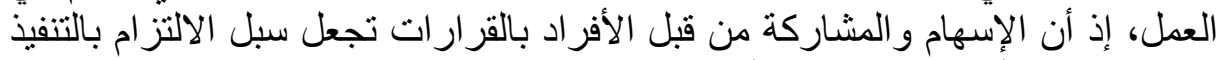

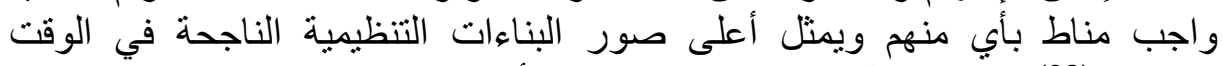

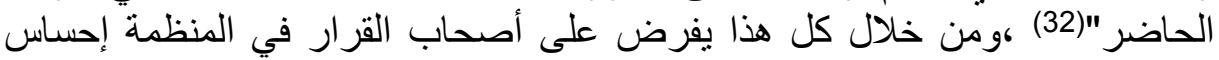

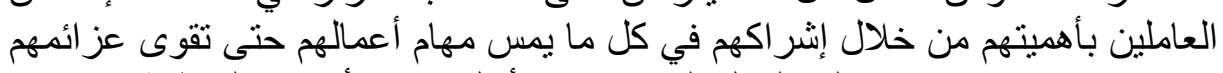

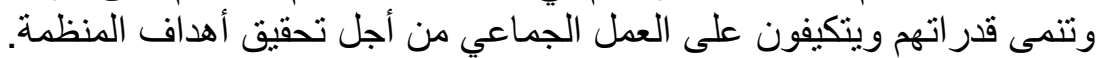

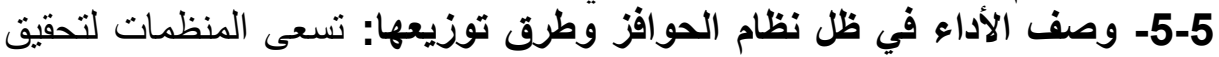

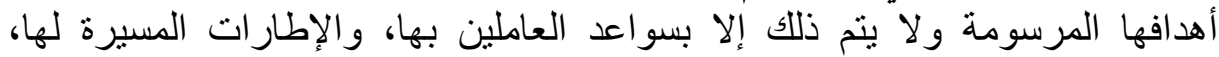

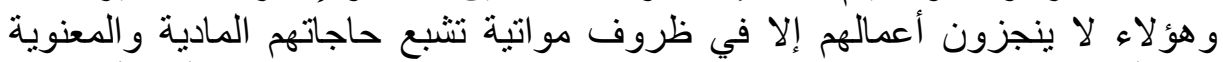

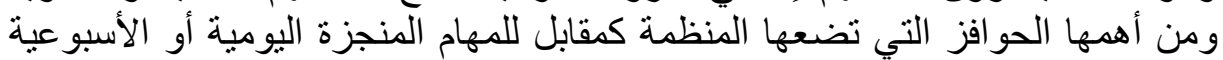

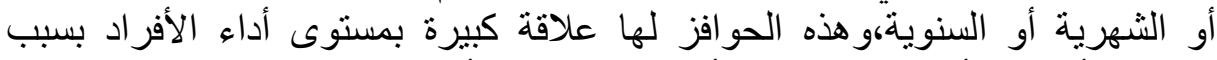

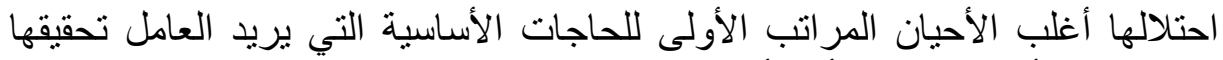

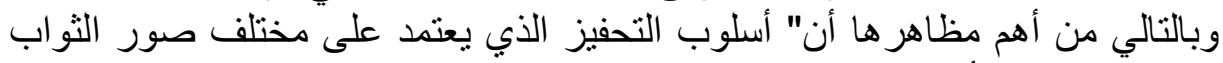

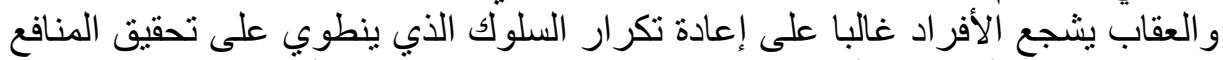

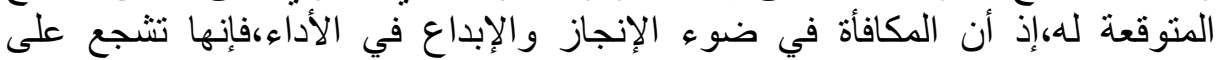

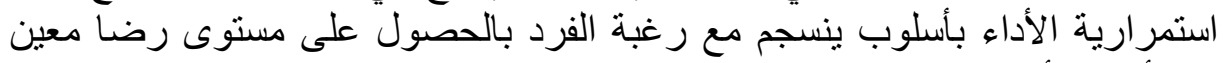

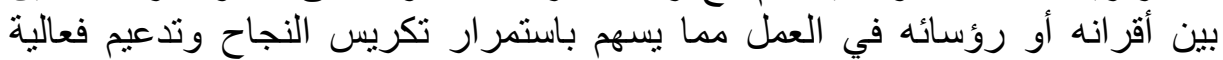

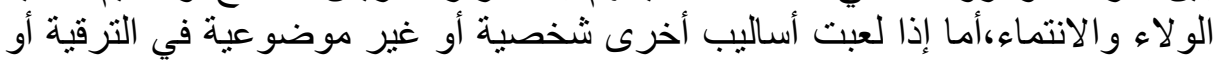

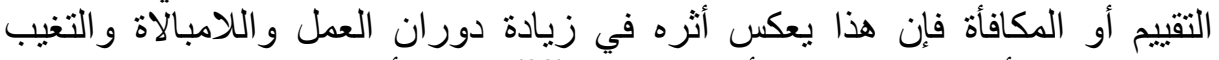

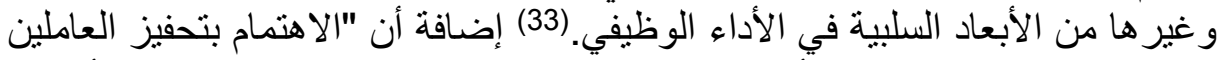

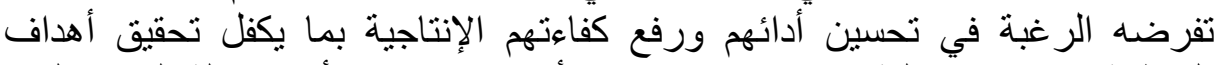

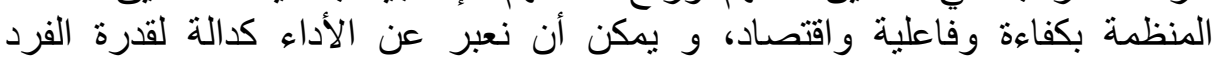

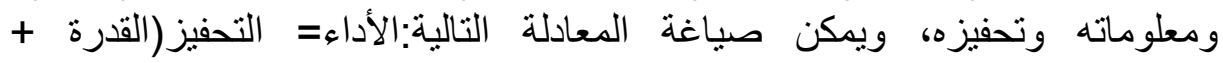




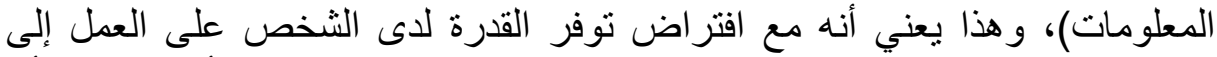

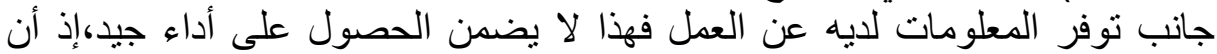

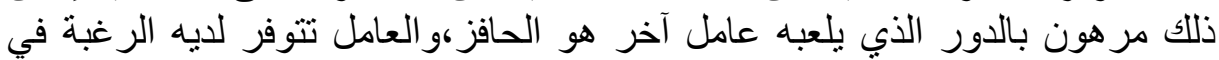

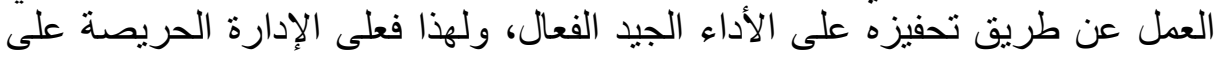

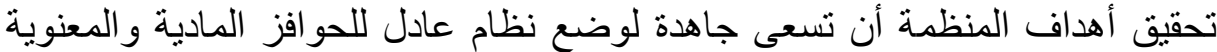
للعاملين".(34) يمكن القول إذن أن للحوافز علاقة ارتباطية قوية برفية برفع مستوى أداء

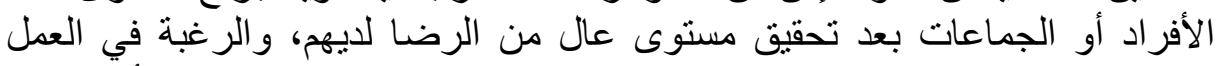

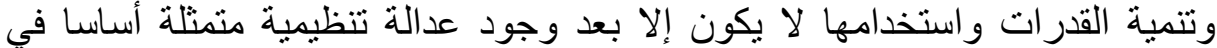
التحفيز الجيد الذي يخلف آثار التمانثى و أهداف التهد المنظمة والأفر اد.

خاتمة: من خلال ما تم ذكره من العناصر تزداد أهمية وجود مناخ تنظيمي صحي في العي التئي

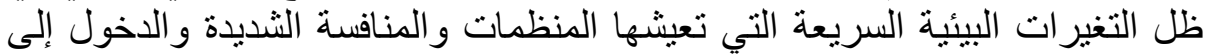

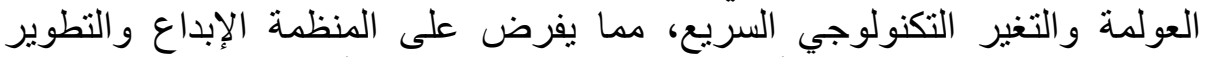

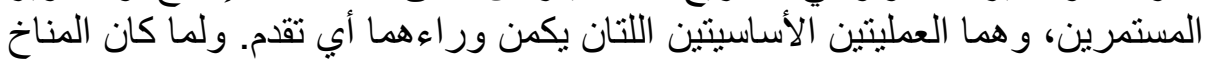

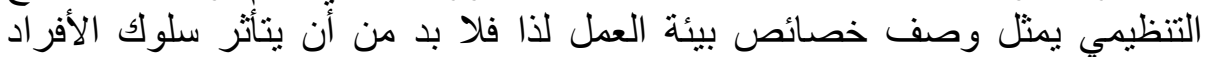

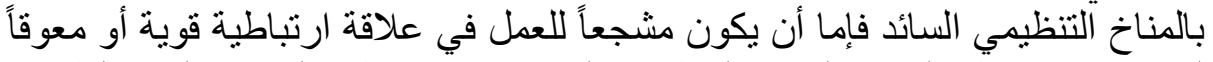

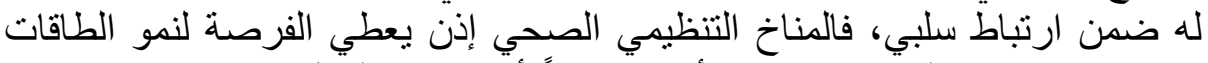

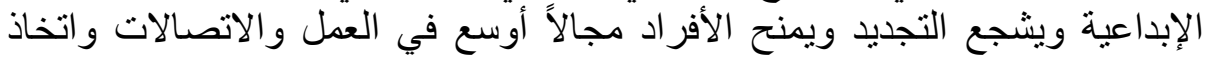

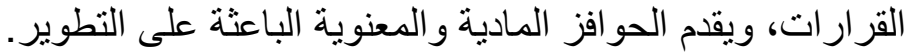

(1) علي السلمي، إدارة السلوك الإنساني في التنظيه، دار غريب، القاهرة، 2004،ص

محمد علي شهيب، السلوك الإنساني في التظيم،دار الفكر

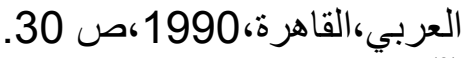

محمد حسن رسمي، السلوك التنظيمي في الإدارة التربوية، دار الوفاء،

(4) فاروق عبد فليه محمد، عبد المجيد السيد، السلوك التنظيمي في إدارة المؤسسات

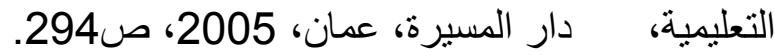

محمد الصيرفي، الموسوعة العلمية للسلوك التظيهي، المكتب الجامعي

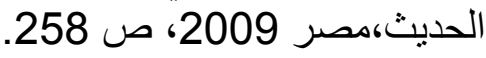

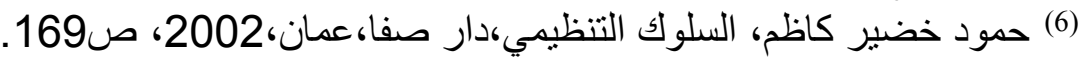

(7) حريم ،حسين محمود، تصميم المنظمة_الهيكل التنظيمي وإجراءات التيكات العمل، دار

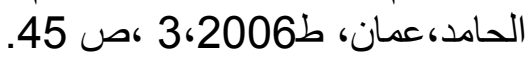

رسمي محمد حسن، السلوك التنظيمي في الإدارة التربوية، دار الوفاء،

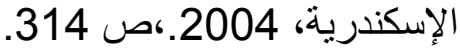

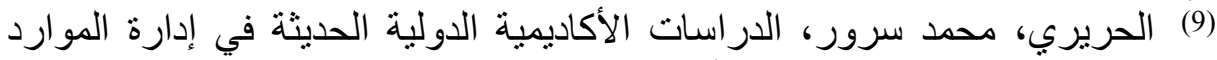

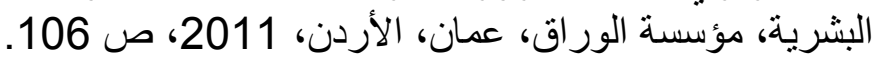

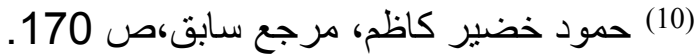

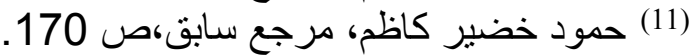

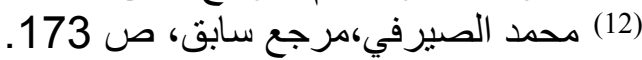

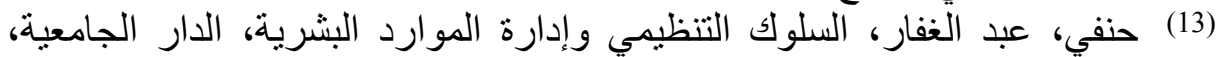

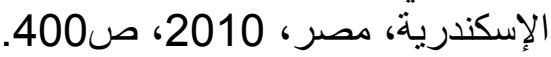

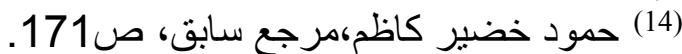

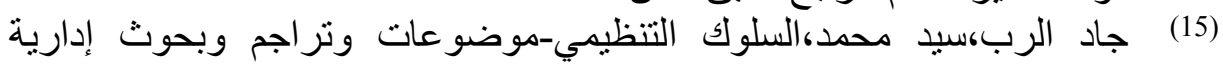




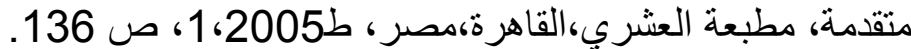

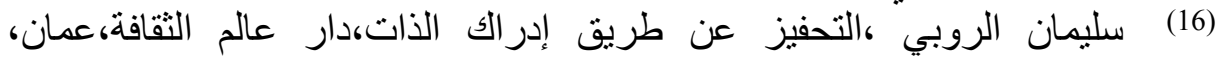

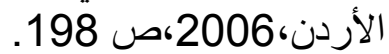
(17) عبد الفتاح عبد الحميد المغربي ، الاتجاهات الحديثة في در اسات وممارسات إدارة

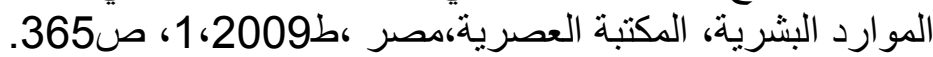

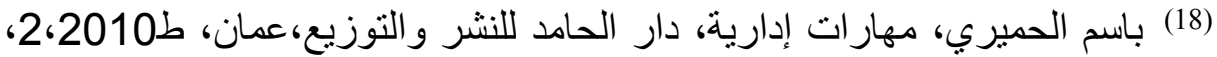

(19) قاسم نايف علوان،نجوى رمضان أحمد، إدارة الوقت، دار الثقافة للنشر

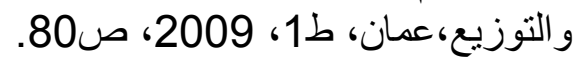

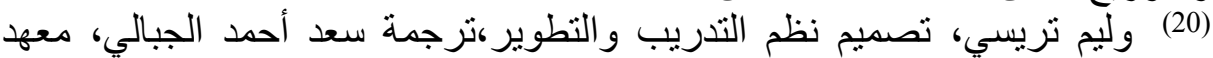

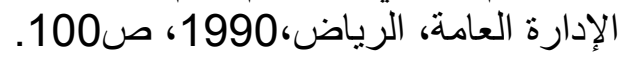

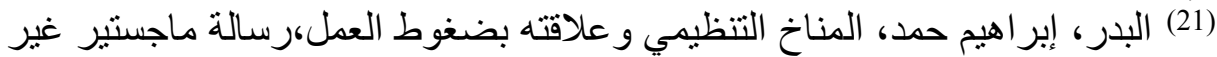

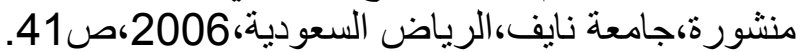

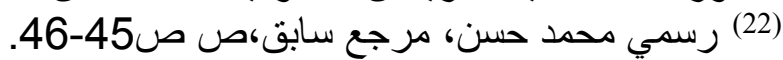

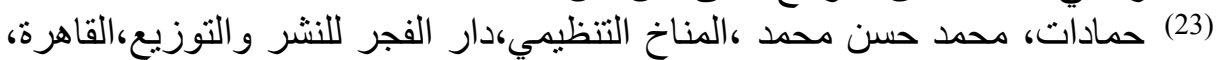

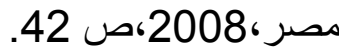
(24) حمود خضير كاظم،السلوك التنظيمي، دار صفاء،الأردن ،ط2002،1، ص

(25) فلية فاروق عبده،عبد المجيد السيد محمد،السلوك التنظيمي في إدارة المؤسسات

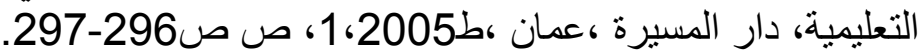

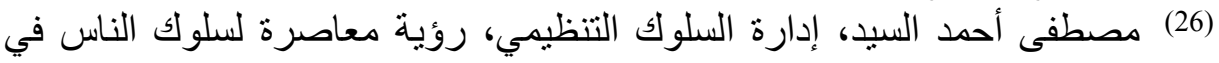

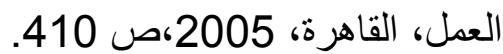
(27) حريم حسين، السلوك التنظيمي(سلوك الأفر اد و الجماعات في منظمات الأعمال)،

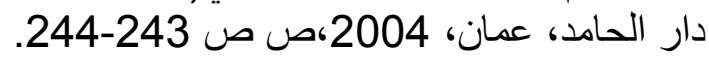

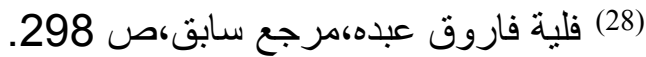
(29) ماهر أحمد، السلوك التنظيمي، مدخل بناء المهار المهار، الدار الجامعية، الإسكندرية،

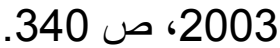

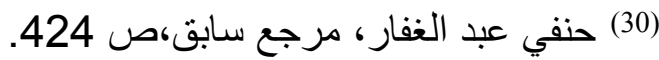

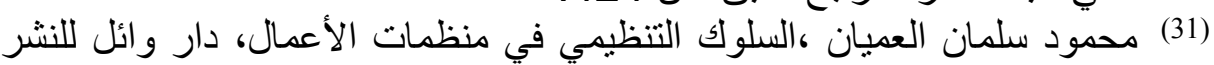

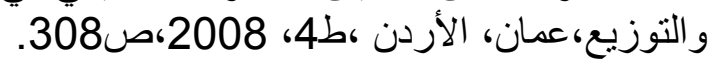

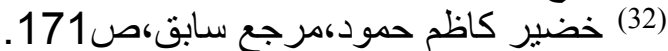

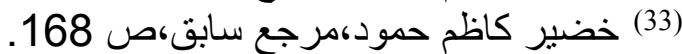

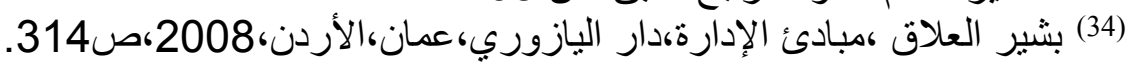

